\title{
OPTIMIZATION OF DYNAMIC VIBRATION ABSORBERS BASED ON EQUAL-PEAK THEORY
}

\author{
Vinícius Piccirillo ${ }^{\mathrm{a} *}$ (1) \\ Angelo Marcelo Tusset ${ }^{\mathrm{a}}$ \\ José Manoel Balthazara \\ a Universidade Tecnológica Federal do Paraná (UTFPR), Ponta Grossa, PR, Brasil. E-mail: piccirillo@utfpr.edu.br, a.m.tusset@gmail.com, \\ jmbaltha@gmail.com \\ *Corresponding author
}

http://dx.doi.org/10.1590/1679-78255285

\begin{abstract}
The present paper proposes a new procedure to determine the optimal parameters of a dynamic vibration absorber (DVA), considering both damped and undamped primary system. The DVA design is formulated as an optimization problem in which the objective function is constructed based on Den Hartog's equal-peak method. The DVA parameters are selected to minimize the response of the primary system when it is subjected to harmonic force or base motion. Firstly, we propose a numerical strategy based on Frequency Response Curve (FRC) in which the parameters of the absorber are updated by minimizing the objective function. The results are presented for a set of reference parameters, which demonstrate the feasibility of the proposed method for determining the optimal parameters of the absorber for both excitations. Taking into account the system response with respect to reference parameters, the bilinear interpolation technique was employed in order to obtain explicit formulas of the damping and frequency ratios of the DVA.
\end{abstract}

\section{Keywords}

Dynamic vibration absorber, Equal-Peak method, Optimization, Frequency response curve, Bilinear interpolation.

\section{INTRODUCTION}

Dynamic vibration absorbers (DVAs) are devices used to reduce the vibration amplitudes of a primary system at certain frequencies, especially close to the resonant frequency. The DVA can be characterized by as a mass-damperspring system that when correctly tuned, reduces the steady-state motion of the primary vibratory system. The first design of an absorber was made by Frahm in 1909, and this first DVA did not have a damping element, only a second mass was attached to the principal one via a secondary spring. This first DVA proved to be effective in a small range of frequencies very close to the natural frequency of the principal system (or also called primary system). When the primary system is excited with a frequency close to natural one, the amplitudes are significantly reduced due to the presence of the DVA, if compared with the results of the primary system without the absorber. However, in this coupled system two resonant frequencies appear one before and other after the resonant frequency of the original system. This kind of system was called a tuned mass damper (TMD).

In order to extend the frequency range and improve the response of the primary system, Den Hartog (1943) proposed a damped DVA. In his design, Den Hartog gave optimal parameters of the DVA, where an analytical solution for the frequencies corresponding to the two maxima of the frequency response curve is determined. It is possible to 
say that a DVA is optimal (in the Den Hartog sense) if it minimizes the maximum vibration amplitude of the main mass, and besides that the magnitude at these two points are equal. This strategy was known as the equal-peak method.

The study of linear absorbers with the undamped primary system is well-established and the first work about syntonization of an optimal absorber was performed by Ormondroyd and Den Hartog (1928). In this work, the authors showed that the introduction of a damper not only dissipates energy but also increases the frequency interval over which the device is effective. A large number of works have been devoted to the study of both linear and nonlinear aspects of DVAs (Shaw et al. (1989), Pai and Schulz (2000), (Oueini and Nayfeh (2000), Ashour and Nayfeh (2003), Viguié and Kerschen (2009), Habib et al. (2015)). The responses of many systems have been studied treating the main aspects of the primary system with DVA devices. Absorbers have been applied on vibration reduction in beams (Cheung and Wong (2008), Ouled Chtiba et al (2010a)), vibration control of structure excited by ground motion (Wong and Cheung (2008), Oliva et al. (2017)), under random loads (Guo et al. (2002)), DVA with viscoelastic connections (De Espíndola et al. (2008), Doubrawa Filho (2011)), DVA with hysteretic connections (Piccirillo et al. (2016), Carpineto et al. (2014), Elahinia et al. (2005)). Since the work of Den Hartog which found an analytical optimal solution for an undamped primary system, most studies focus on the numerical optimization techniques for more complex singledegree-of-freedom vibration absorber models, especially damped vibration absorbers. In Jordanov and Cheshankov (1988) considers the use of nonlinear programming techniques to obtain the optimal tuning and damping parameters for DVAs with both linear and nonlinear springs. In Thompson (1980) and Thompson (1981) presents studies where the frequency locus method is used to describe the optimal damper parameters that would minimize the main system response as well as the motion of the absorber. In Viana et al. (2008) uses the ant colony optimization technique to arrive at the optimal parameters of a vibration absorber. In Pennestri (1998) applied a Chebyshev's min-max criterion for finding the optimal damper parameters, and others numerical studies based on minimax optimization are reported in (Ouled Chtiba et al. (2010b), Randall et al. (1981), Brown and Singh (2011).

In this context, the main objective of the present paper is to develop a linear absorber that can mitigate the vibrations of a linear primary system considering either harmonic force or base motion. First, for set parameters, the damping of the absorber and the frequency ratio between the primary system and the absorber are obtained by a numerical optimization process. Second, based on system response with respect to reference parameters, the bilinear interpolation technique was employed in order to obtain explicit formulas of the damping and frequency ratios of the DVA. It is worth mentioning here that the optimal solution is always in the Den Hartog sense, namely, the two peaks generated with the introduction of the absorber has set equal level.

The paper is organized as follows. Section 2 presents the equations of motion of the DVA considering the harmonic force and base-excitation. In Section 3, a brief discussion about the equal peak methodology is done. In Section 4, a numerical methodology for tuning the DVA is developed. Numerical results of the system behavior are presented in Section 5. In section 6 the bilinear interpolation is used to obtain analytical formulas for the absorber damper and frequency ratio. Section 7 was made a comparison between the strategy proposed here and others that can be found in the literature. The conclusions of the study are drawn in Section 8.

\section{MATHEMATICAL MODEL}

Figure 1 shows a schematic model of the DVA, where $m_{1}$ and $m_{2}$ are the masses of the structure and DVA, respectively, and $k_{1}$ is the stiffness of the primary structure and $k_{2}$ is the stiffness of the absorber connected to the primary structure. We further assume that the structure has a linear viscous damping with damping coefficient $c_{1}$, while $c_{2}$ is the damping coefficient of the DVA. The displacement of the structure is denoted by $x_{1}$, while the displacement of the absorber is denoted by $x_{2}$. We considered two systems: one with harmonic force $F(t)=F_{0} \cos (\omega t)$ directly applied to the primary mass $m_{1}$ (figure $1(\mathrm{a})$ ), and the other system is harmonically excited by a displacement $x_{0}(t)=F_{1} \cos (\omega t)$ applied to the base of the primary system (figure $1(\mathrm{~b})$ ), where we assuming that $F_{1}=\frac{F_{0}}{k_{1}}$. 


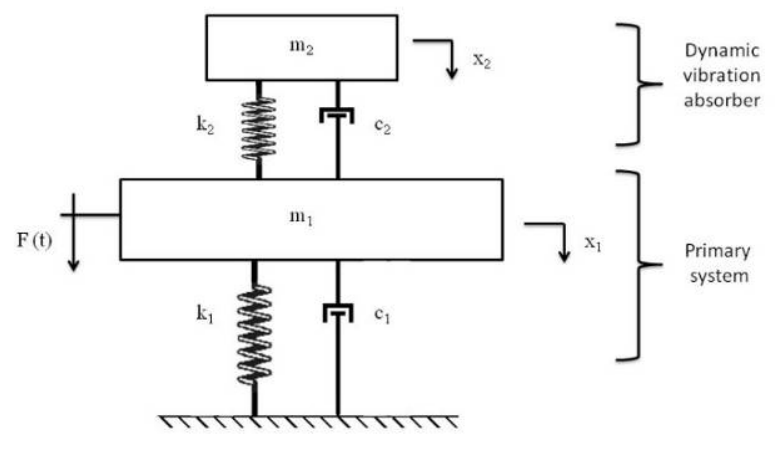

(a)

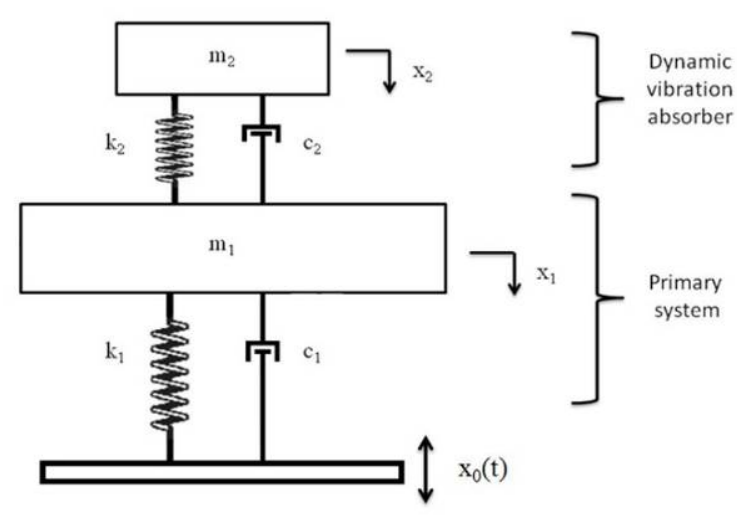

(b)

Figure 1: Primary system with viscous damped DVA (a) Force excitation system and (b) Motion excitation system

The equations of motion of the system with DVA for the harmonic force (equation 1) and base-excitation (equation 2) assumes the form

$m_{1} x_{1}^{\prime \prime}+c_{1} x_{1}^{\prime}+c_{2}\left(x_{1}^{\prime}-x_{2}^{\prime}\right)+k_{1} x_{1}+k_{2}\left(x_{1}-x_{2}\right)=F_{0} \cos (\omega t)$

$m_{2} x_{2}^{\prime \prime}+c_{2}\left(x_{2}^{\prime}-x_{1}^{\prime}\right)+k_{2}\left(x_{2}-x_{1}\right)=0$

$m_{1} x_{1}^{\prime \prime}+c_{1} x_{1}^{\prime}+c_{2}\left(x_{1}^{\prime}-x_{2}^{\prime}\right)+k_{1} x_{1}+k_{2}\left(x_{1}-x_{2}\right)=k_{1} x_{0}+c_{1} x_{0}^{\prime}$

$m_{2} x_{2}^{\prime \prime}+c_{2}\left(x_{2}^{\prime}-x_{1}^{\prime}\right)+k_{2}\left(x_{2}-x_{1}\right)=0$

For our purposes, it is worth to rewrite the equations (1) and (2) in nondimensional form, by incorporating the following dimensionless parameters,

$\tau=\omega_{1} t, u_{1}=\frac{x_{1}}{x_{s t}}, u_{2}=\frac{x_{2}}{x_{s t}}$

where $x_{s t}$ means a static displacement of the system, $u_{1}$ and $u_{2}$ are the nondimensional displacements of the main mass $m_{1}$ and $m_{2}$, respectively, $\tau$ is the nondimensional time, $\omega_{1}$ and $\omega_{2}$ are the natural frequencies of the primary system and the absorber, respectively. Substitution of the equation (3) into the equations (1) and (2), the nondimensional form of the equations of motion are obtained

$\ddot{u}_{1}+2 \xi_{1} \dot{u}_{1}+2 \xi_{2} \mu \varepsilon\left(\dot{u}_{1}-\dot{u}_{2}\right)+u_{1}+\mu \varepsilon^{2}\left(u_{1}-u_{2}\right)=A \cos (\Omega \tau)$

$\ddot{u}_{1}+2 \xi_{2} \varepsilon\left(\dot{u}_{2}-\dot{u}_{1}\right)+\varepsilon^{2}\left(u_{2}-u_{1}\right)=0$

$\ddot{u}_{1}+2 \xi_{1} \dot{u}_{1}+2 \xi_{2} \mu \varepsilon\left(\dot{u}_{1}-\dot{u}_{2}\right)+u_{1}+\mu \varepsilon^{2}\left(u_{1}-u_{2}\right)=A\left(\cos (\Omega \tau)-2 \zeta_{1} \Omega \sin (\Omega \tau)\right)$

$\ddot{u}_{1}+2 \xi_{2} \varepsilon\left(\dot{u}_{2}-\dot{u}_{1}\right)+\varepsilon^{2}\left(u_{2}-u_{1}\right)=0$

where

$\omega_{1}=\sqrt{\frac{k_{1}}{m_{1}}}, \omega_{2}=\sqrt{\frac{k_{2}}{m_{2}}}, 2 \xi_{1}=\frac{c_{1}}{m_{1} \omega_{1}}, 2 \xi_{2}=\frac{c_{2}}{m_{2} \omega_{2}}, \varepsilon=\frac{\omega_{2}}{\omega_{1}}=\frac{1}{\sqrt{\mu}} \sqrt{\frac{k_{2}}{k_{1}}}$, 
$A=\frac{F_{0}}{m_{1} \omega_{1}^{2} x_{s t}}, \Omega=\frac{\omega}{\omega_{1}}, \mu=\frac{m_{2}}{m_{1}}$.

\section{DYNAMIC VIBRATION ABSORBER - EQUAL-PEAK METHOD}

The first study about a device designed to suppress the vibration amplitudes of a primary system (case 1) was performed by Frahm (1909). The idea was to consider an undamped linear TMD attached to an undamped linear oscillator (see figure $1(\mathrm{a})$ with $c_{1}=c_{2}=0$ ). In this design, the choice of the values of mass and stiffness of the absorber is based on tuning between the natural frequency of the absorber and the frequency of the harmonic excitation which value is fixed. In this sense, this absorber is efficient in a narrow frequency range close to the resonance frequency, which tends to lose efficiency when the excitation frequency changes and the TMD is no longer tuned. In summary, we can say that are two principal strategies to improve this tuning. In order to increase the effective bandwidth and decrease the resonance peak, i.e., improving the performance of the TMD, Den Hartog found analytical formulas to frequency and damping ratios to a damped DVA (i.e., $c_{2} \neq 0$ ). The other strategy is to find the optimal values of the absorber based on numerical optimization procedures. This strategy is mainly used in DVA coupled to a dissipative linear oscillator (i.e., $c_{1} \neq 0$ ).

In his classical study (case 1), Den Hartog (1943) showed that the frequency-amplitude response curves of the undamped primary mass always pass through two invariant points ( $P$ and $Q$ ) independent of the absorber damping. Den Hartog proposed to optimize the parameters of the absorber in such a way to have two fixed points in the FRC at the same amplitude. This methodology was called the equal-peak method and, under such circumstances, Den Hartog (1943) derived approximate analytic formulas for the absorber stiffness and damping, respectively. The optimal frequency ratio $\varepsilon$ (i.e., the ratio between the frequency of the TMD and main structure) and optimal damping ratio $\xi$ of the TMD can be expressed as

$\varepsilon^{o p t}=\frac{\omega_{2}}{\omega_{1}}=\frac{\sqrt{k_{2} m_{1}}}{\sqrt{k_{1} m_{2}}}=\frac{1}{1+\mu}, \xi^{o p t}=\frac{c_{2}}{2 m_{2} \omega_{2}}=\sqrt{\frac{3 \mu}{8(1+\mu)^{3}}}$

where $\mu$ is the mass ratio (i.e., relation between the absorber mass and the main mass).

To illustrate this method, we shall consider that the absorber mass is $5 \%$ of the main mass, therefore $\mu=0.05$, and using the equation (4) the optimized parameters $\varepsilon^{o p t}$ and $\xi_{2}^{o p t}$ are 0.9524 and 0.1273 , respectively. As illustrated in figure 2, this tuning condition minimizes the maximum response amplitude of the primary system, and according to equation (6) the optimal value of $\xi_{2}$ is 0.1273 (equal-peak method); besides, it is possible to observe two invariant points ( $P$ and $Q$ ) (see figure $2(b)$ ).
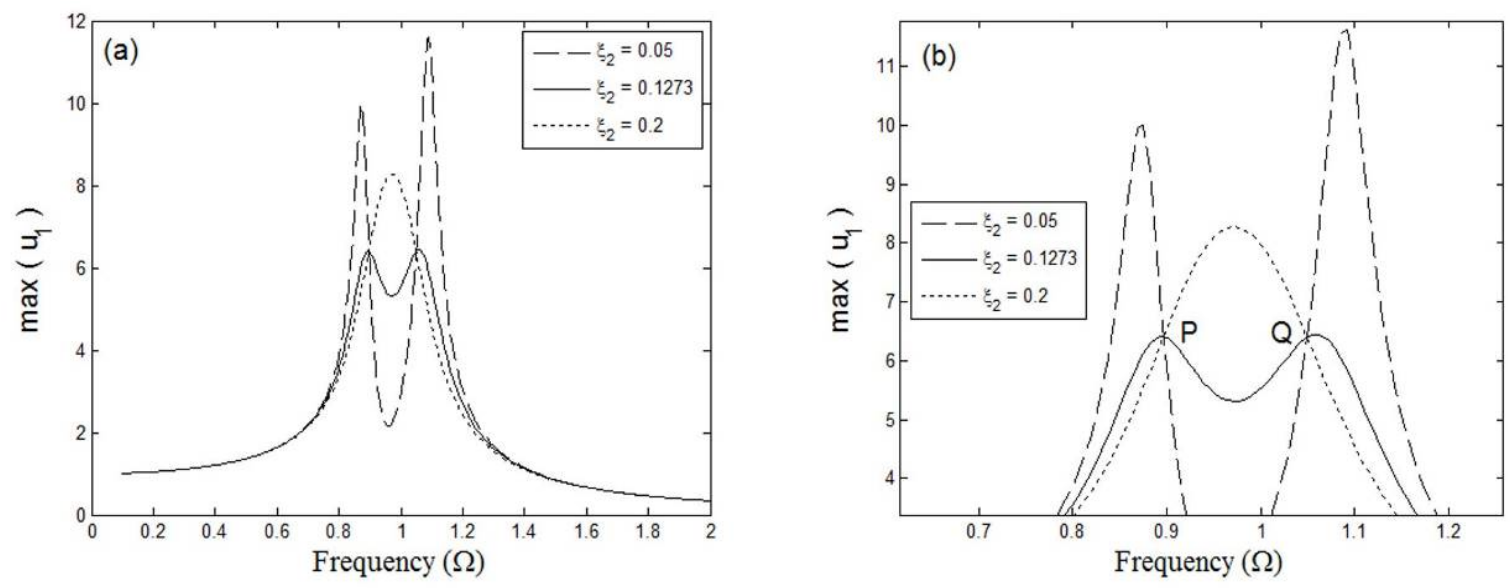

Figure 2: (a) Frequency Response Curves for various values of the damping ratio $\xi_{1}=0\left(c_{1}=0\right)$, and (b) zoom of a particular region of the Fig. (a)

The optimization theory of linear absorbers when $\xi_{1}=0\left(c_{1}=0\right)$ is well-established (see figure 2$)$. On the other hand, if $\xi_{1} \neq 0\left(c_{1} \neq 0\right)$ the two peaks are not at the same level, and therefore, the optimal solution (equal peaks) cannot be derived using the parameter of the equation 6 . A comparison of the results obtained with $\xi_{1} \neq 0\left(c_{1} \neq 0\right)$ and $\xi_{1}=0\left(c_{1}=0\right)$ is shown in figure 3. Note that, as expected, when $\xi_{1} \neq 0\left(c_{1} \neq 0\right)$ the two peaks are not equal. 

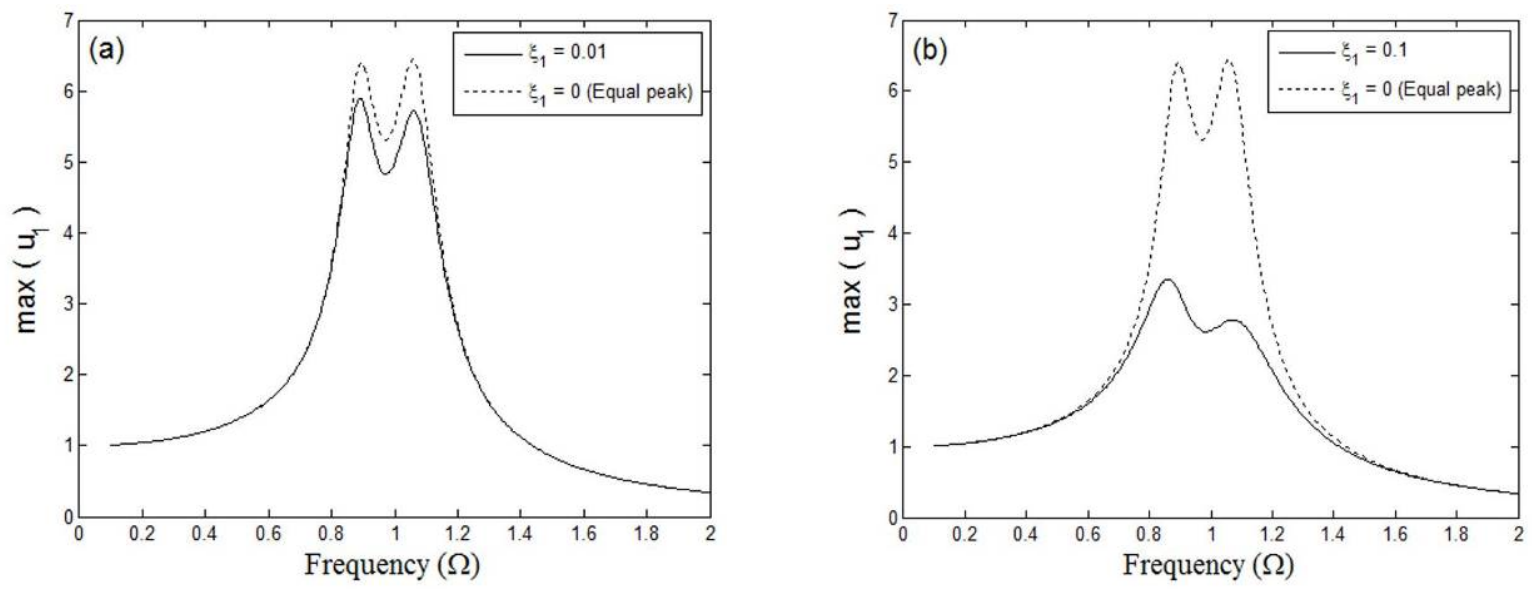

Figure 3: Frequency Response Curves. (a) $\xi_{1}=0.01$ and (b) $\xi_{1}=0.1$

As mentioned before, the Den Hartog's theory shows a good accuracy between the peaks in FRC taking into account an undamped primary system, however, for the damped primary system the response is not accurate. In order to obtain equal peaks in FRC of a damped primary system $\left(\xi_{1} \neq 0\left(c_{1} \neq 0\right)\right)$, we formulate a numerical optimization problem to find the set of physical parameters of the absorber. This procedure will be described in the next section.

\section{OPTIMIZATION PROCEDURE}

The optimization objective is; for any value of mass relation, $\mu$, we will find the optimal values of the damping ratio coefficient $\left(\xi_{2}\right)$, and frequency ratio $(\varepsilon)$. Therefore, the optimization problem for the primary system with attached DVA can be described as:

Find the design variables: $\xi_{2}$ and $\varepsilon$

To minimize: $J$ (7)

Subjected to: $\xi_{2}^{\text {low }} \leq \xi_{2} \leq \xi_{2}^{\text {up }}, \varepsilon^{\text {low }} \leq \varepsilon \leq \varepsilon^{\text {up }}$ where $\xi_{2}^{\text {low }}, \xi_{2}^{u p}, \varepsilon^{\text {low }}, \varepsilon^{\text {up }}$ are the respective lower and upper bounds of the absorber damping and frequency, and $J$ is a functional that must be defined. Note that in this case, the mass ratio $\mu$, is a given input in the optimization problem.

\subsection{Proposed optimal criterion}

Based on what was discussed earlier, the original resonance frequency of the primary system is eliminated with the inclusion of the absorber. As a consequence, two new resonance peaks are observed in FRC. This situation is illustrated in figure 4 , where the second mass is attached to the primary system and two resonance emerges from the FRC curve. The peaks are denoted by $A:=A\left(\Omega_{\mathrm{A}}, \mathrm{u}_{1}\left(\Omega_{\mathrm{A}}\right)\right)$ and $B:=B\left(\Omega_{\mathrm{B}}, \mathrm{u}_{1}\left(\Omega_{\mathrm{B}}\right)\right)$, where $\Omega_{\mathrm{A}}\left(\right.$ or $\left.\Omega_{\mathrm{B}}\right)$ is the frequency value at point $\mathrm{A}$ (or $\mathrm{B}$ ), and $\mathrm{u}_{1}\left(\Omega_{\mathrm{A}}\right)$ (or $\left.\mathrm{u}_{1}\left(\Omega_{\mathrm{B}}\right)\right)$ is defined, with some notation abuse, as the maximum value of the state $\mathrm{u}_{1}$ when $\Omega=\Omega_{\mathrm{A}}\left(\right.$ or $\left.\Omega_{\mathrm{B}}\right)$. As it can be seen between the points $\mathrm{A}$ and $\mathrm{B}$ there is a minimum point that we denote by $C:=C\left(\Omega_{\mathrm{C}}, \mathrm{u}_{1}\left(\Omega_{\mathrm{C}}\right)\right)$, besides $\Delta_{\mathrm{AB}}$ represent the distance between the values $\mathrm{u}_{1}\left(\Omega_{\mathrm{A}}\right)$ andu $\mathrm{u}_{1}\left(\Omega_{\mathrm{B}}\right)$, namely, $\Delta_{\mathrm{AB}}:=\left|\mathrm{u}_{1}\left(\Omega_{\mathrm{A}}\right)-\mathrm{u}_{1}\left(\Omega_{\mathrm{B}}\right)\right|$. 


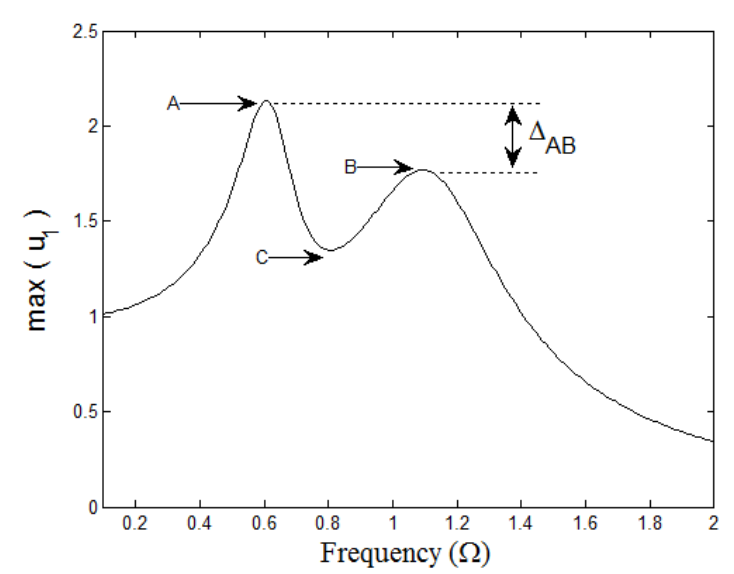

Figure 4: Frequency Response Curve of the primary system

As stated before, the optimization objective (in a Den Hartog sense) is obtain equal peaks of the primary system response when subjected to harmonic or base motion excitation. The numerical problem discussed in this paper is therefore to find the optimal values of $\xi_{2}$ and $\varepsilon$, from which, the steady-state peaks $u_{1}\left(\Omega_{\mathrm{A}}\right)$ and $\mathrm{u}_{1}\left(\Omega_{\mathrm{B}}\right)$ are in the same level, i.e., $\Delta_{\mathrm{AB}} \approx 0$. Besides, will try to maximize the value $\mathrm{u}_{1}\left(\Omega_{\mathrm{C}}\right)$, or equivalently, minimize the value of $\frac{1}{\mathrm{u}_{1}\left(\Omega_{\mathrm{C}}\right)^{\prime}}$, therefore, this was included as an additional criteria. In other words, one should seek the optimal value of the absorber parameters $\xi_{2}$ and $\varepsilon$ in the form of

$\min _{\xi_{2}, \varepsilon} J:=\min _{\xi_{2}, \varepsilon}\left(\Delta_{\mathrm{AB}}+\frac{1}{\mathrm{u}_{1}\left(\Omega_{\mathrm{C}}\right)}\right)$

Then, the optimization problem is reformulated as

$\min _{\xi_{2}, \varepsilon}\left(\Delta_{\mathrm{AB}}+\frac{1}{\mathrm{u}_{1}\left(\Omega_{\mathrm{C}}\right)}\right)$

subject to constraints:

$\xi_{2}^{\text {low }} \leq \xi_{2} \leq \xi_{2}^{u p}$

$\varepsilon^{\text {low }} \leq \varepsilon \leq \varepsilon^{u p}$

Once defined the functional $J$, is possible to describe the idea of the optimization. Initially, the absorber parameters $\xi_{2}$ and $\varepsilon$ must be guessed and the equation (4) (or equation (5)) must be solved using a numerical method (here, the 5th-order Runge-Kutta algorithm (RK5) is used), to determine the FRC curve. Just to clarify, the FRC is calculated as follows: by varying the parameter $\Omega \in[0.1,2]$, the system is numerically integrated, and the maximum amplitude of the primary system $\max \left(u_{1}\right)$ is evaluated for each value of $\Omega$. In the next step, the points $A\left(\Omega_{\mathrm{A}}, \mathrm{u}_{1}\left(\Omega_{\mathrm{A}}\right)\right)$ and $B\left(\Omega_{\mathrm{B}}, \mathrm{u}_{1}\left(\Omega_{\mathrm{B}}\right)\right.$ ), are determined in FRC (see figure 4 ). If $\Delta_{\mathrm{AB}} \leq \delta$ ( $\delta$ is given according to the accuracy of the desired response) and $\Omega_{\mathrm{A}} \neq \Omega_{\mathrm{B}}$ then, an optimal solution is found, otherwise, only two possibilities are possible, either, $A=B$ (only one peak is found in FRC) or $A \neq B$ (two peaks are found but $\Delta_{\mathrm{AB}}>\delta$ ). Considering that $A \neq B \Rightarrow \Omega_{\mathrm{A}} \neq \Omega_{\mathrm{B}}$ and $\mathrm{u}_{1}\left(\Omega_{\mathrm{A}}\right) \neq \mathrm{u}_{1}\left(\Omega_{\mathrm{B}}\right)$ then, two peaks are found, and the next step is to find the point $C\left(\Omega_{\mathrm{C}}, \mathrm{u}_{1}\left(\Omega_{\mathrm{C}}\right)\right)$ in FRC curve, and therefore, the objective function $J$, described in equation (9) subject to constraints given in equations (10) and (11) are evaluated. During the minimization of the objective function, the value of $\xi_{2}$ and $\varepsilon$ are changing, and for each new value found, the equation (4) (or equation (5)) is numerically solved. This step is repeated until the functional $J$ reach the minimum. The procedure is then repeated until satisfies the conditions $\Delta_{\mathrm{AB}} \leq \delta$ and $\Omega_{\mathrm{A}} \neq \Omega_{\mathrm{B}}$.

It is worth mentioning here that depending on the choice values of the absorber parameters the FRC can present only one peak, for example, if $\xi_{2}$ assumes a high value, the two masses are virtually clamped and we have a system equivalent to a single-degree-of-freedom system. This situation is illustrated in figure 5 , so it should be taken into 
account as well. Considering that $A=B \Rightarrow \Omega_{\mathrm{A}}=\Omega_{\mathrm{B}}$ and $\mathrm{u}_{1}\left(\Omega_{\mathrm{A}}\right)=\mathrm{u}_{1}\left(\Omega_{\mathrm{B}}\right)$, namely, only one peak is found, we define a new functional $L$, that minimizes the amplitude of this peak.

$\min _{\xi_{2}, \varepsilon} \mathrm{L}:=\min _{\xi_{2}, \varepsilon}\left(\max \left(\mathrm{u}_{1}\left(\Omega_{\mathrm{A}}\right)\right)\right)$

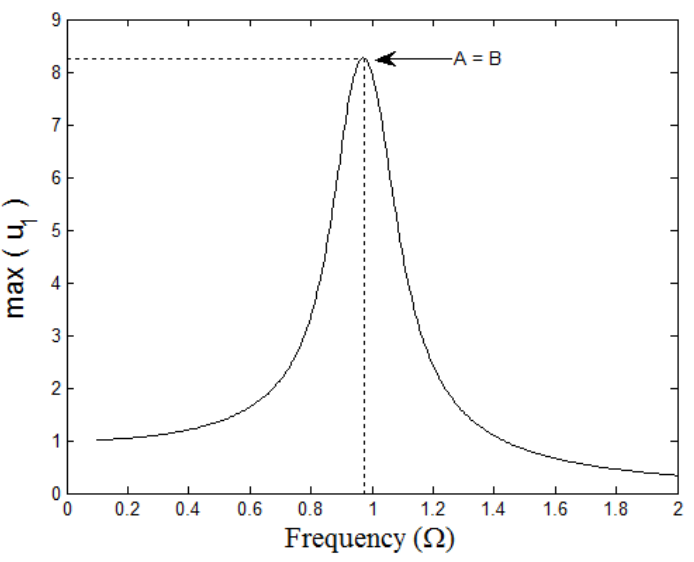

Figure 5: Frequency Response Curve of the primary system

Here, all the steps are similar to described before. In both cases, we used the interior-point algorithm to determine an optimal solution. Figure 6 shows a flowchart of the proposed algorithm for solving the optimization problem, and figure 7 shows a flowchart as regards to block 1 and block 2, found inside of figure 6 . 


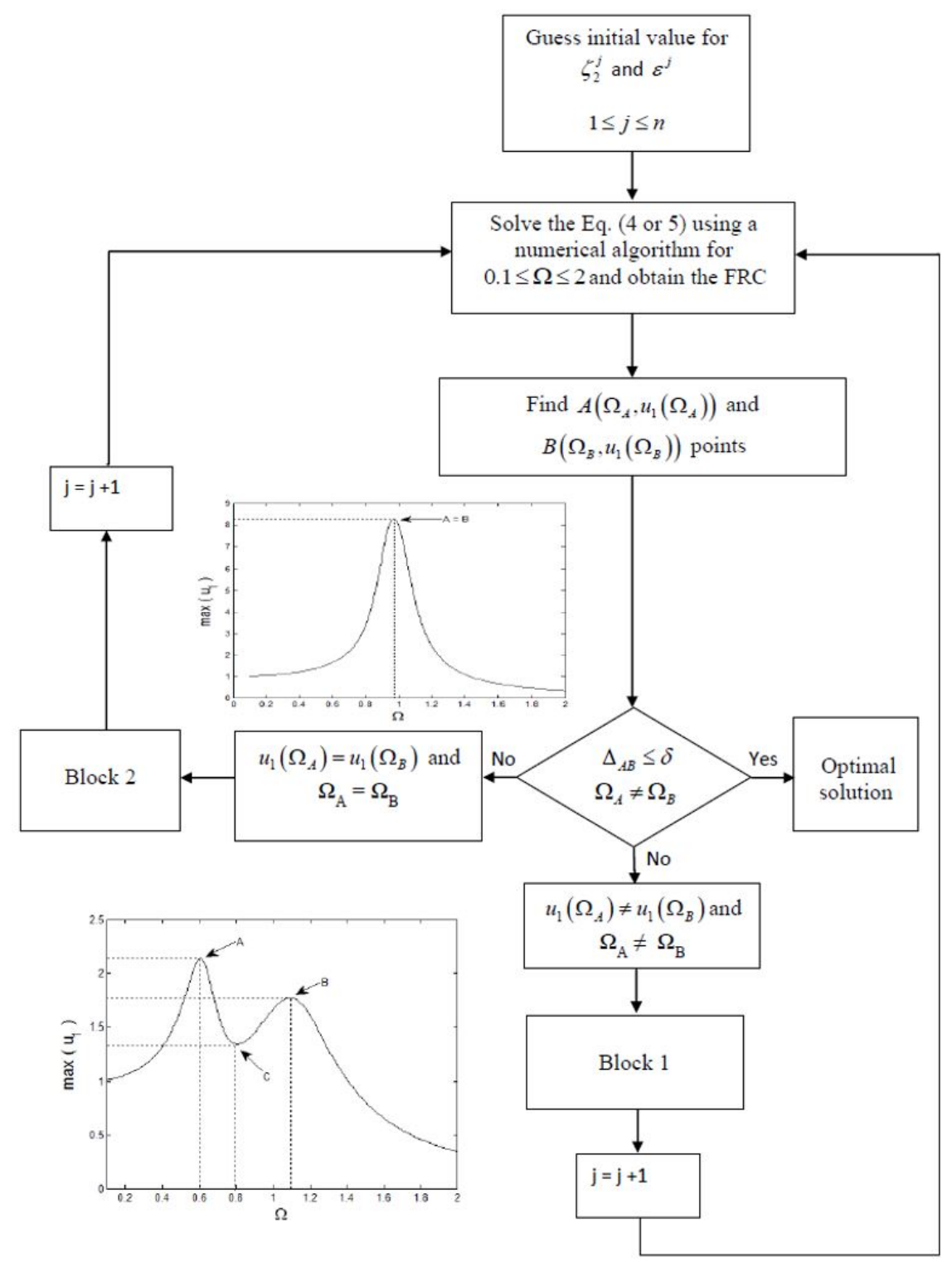

Figure 6: Flowchart of the optimization algorithm

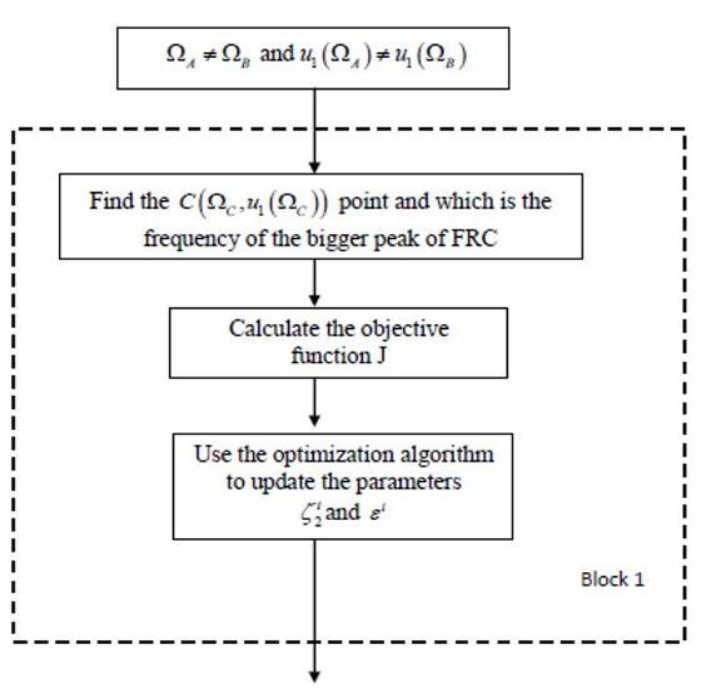

(a)

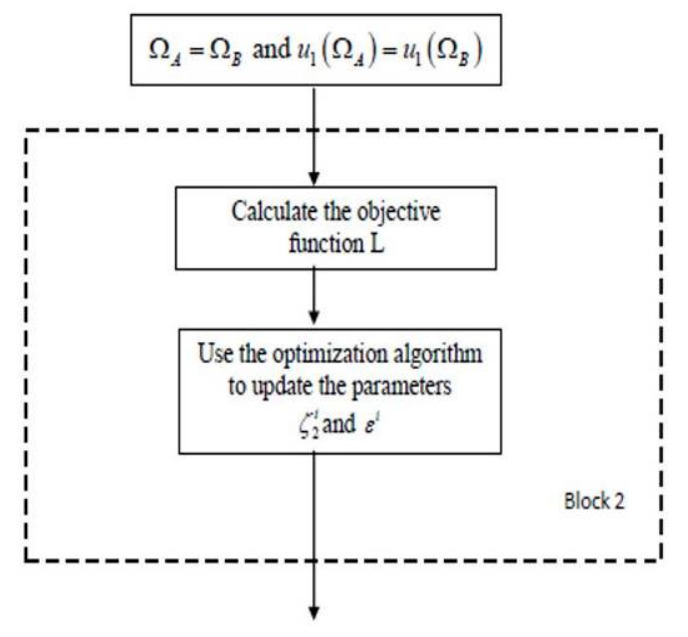

(b)

Figure 7: (a) Flowchart of the Block 1 and (b) Flowchart of the Block 2 


\section{NUMERICAL RESULTS}

In order to verify the effectiveness and validity of the proposed methodology, we provide some numerical examples, one may assume that $A=1$ and other parameters will be changed. In all simulations we chose $\delta \leq 10^{-2}$, that is, the optimal solution will be found when the difference between the two peaks is equal to this order. In this section, we will obtain the optimal values of $\varepsilon$ and $\xi_{2}$ to undamped and damped primary system.

The system of equations (4) and (5) was numerically integrated for a several selected mass ratio, $\mu$, and damping coefficient, $\xi_{1}$, of the primary system. After selecting the value of $\mu$ and $\xi_{1}$, the optimization procedure, described by figures 6 and 7, is carried out in order to obtain the corresponding optimal values of $\varepsilon$ and $\xi_{2}$. For this purpose, let us introduce a set of reference parameters for the combination $\left(\mu, \xi_{1}\right)$. The optimal parameters $\varepsilon^{o p t}$ and $\xi^{\text {opt }}$ has been found for each $\left(\mu, \xi_{1}\right)$, and they are listed in Table 1 and Table 2, respectively. In both tables, the term HE is used to denote harmonic excitation and the term BE refers to base excitation. As can be seen, there are several values of $\mu$ and $\xi_{1}$ where the obtained results of $\varepsilon^{o p t}$ and $\xi^{o p t}$ coincide independent of the excitation (HE or BE). The optimal values coincide especially in the interval $0.0 \leq \xi_{1} \leq 0.04$, that is, the damping ratio $\xi_{1}$ determines how motion is transmitted from the base to the primary mass since the transmissibility is a function of the frequency ratio $\Omega$ and the damping ratio $\xi_{1}$. Namely, if the base excitation is considered and $\xi_{1} \leq 0.04$ the damping effect on the primary system makes the response of the system subject to $\mathrm{BE}$ or HE excitation, close to each other.

Table 1. Optimal frequency ratio of the DVA

\begin{tabular}{|c|c|c|c|c|c|c|c|c|c|c|c|c|}
\hline & & $\xi_{1}=0.0$ & $\xi_{1}=0.01$ & $\xi_{1}=0.02$ & $\xi_{1}=0.03$ & $\xi_{1}=0.04$ & $\xi_{1}=0.05$ & $\xi_{1}=0.06$ & $\xi_{1}=0.07$ & $\xi_{1}=0.08$ & $\xi_{1}=0.09$ & $\xi_{1}=0.1$ \\
\hline$\mu$ & excitation & $\varepsilon^{\text {opt }}$ & $\varepsilon^{\text {opt }}$ & $\varepsilon^{\text {opt }}$ & $\varepsilon^{\text {opt }}$ & $\varepsilon^{\text {opt }}$ & $\varepsilon^{\text {opt }}$ & $\varepsilon^{\text {opt }}$ & $\varepsilon^{\text {opt }}$ & $\varepsilon^{\text {opt }}$ & $\varepsilon^{\text {opt }}$ & $\varepsilon^{o p t}$ \\
\hline \multirow{2}{*}{0.01} & HE & \multirow{2}{*}{0.9901} & \multirow{2}{*}{0.9901} & \multirow{2}{*}{0.9879} & \multirow{2}{*}{0.9860} & \multirow{2}{*}{0.9837} & \multirow{2}{*}{0.9809} & 0.9783 & \multirow{2}{*}{0.9758} & \multirow{2}{*}{0.9728} & 0.9695 & 0.9659 \\
\hline & $\mathrm{BE}$ & & & & & & & 0.9787 & & & 0.9698 & 0.9670 \\
\hline \multirow{2}{*}{0.02} & $\mathrm{HE}$ & \multirow{2}{*}{0.9801} & \multirow{2}{*}{0.9789} & \multirow{2}{*}{0.9768} & \multirow{2}{*}{0.9742} & \multirow{2}{*}{0.9713} & 0.9683 & 0.9652 & \multirow{2}{*}{0.9621} & \multirow{2}{*}{0.9590} & 0.9547 & 0.9518 \\
\hline & $\mathrm{BE}$ & & & & & & 0.9687 & 0.9659 & & & 0.9559 & 0.9523 \\
\hline \multirow{2}{*}{0.03} & $\mathrm{HE}$ & \multirow{2}{*}{0.9709} & \multirow{2}{*}{0.9677} & \multirow{2}{*}{0.9652} & \multirow{2}{*}{0.9623} & \multirow{2}{*}{0.9594} & \multirow{2}{*}{0.9565} & 0.9528 & \multirow{2}{*}{0.9497} & 0.9456 & 0.9426 & \multirow{2}{*}{0.9385} \\
\hline & $\mathrm{BE}$ & & & & & & & 0.9532 & & 0.9469 & 0.9428 & \\
\hline \multirow{2}{*}{0.04} & $\mathrm{HE}$ & \multirow{2}{*}{0.9620} & \multirow{2}{*}{0.9580} & \multirow{2}{*}{0.9551} & \multirow{2}{*}{0.9522} & \multirow{2}{*}{0.9490} & 0050 & ברבחת & 0.9378 & 0.9337 & 0.9296 & 0.9255 \\
\hline & $\mathrm{BE}$ & & & & & & 0.9458 & $0.94 \angle 2$ & 0.9390 & 0.9348 & 0.9309 & 0.9267 \\
\hline ז0م & $\mathrm{HE}$ & 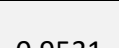 & 0000 & 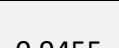 & רבחסת & م000000 & תברח0 & (5) & 0.9267 & 0.9232 & 0.9179 & 0.9135 \\
\hline 0.05 & $\mathrm{BE}$ & גבכנכ. & 0.5400 & בנד & 0.5424 & & 4.534 & כובכנט & 0.9283 & 0.9234 & 0.9196 & 0.9156 \\
\hline ro & $\mathrm{HE}$ & קחת & 0000 & באבחת & ברכחת & חרח 0 & 0.9251 & 0.9209 & 0.9167 & 0.9125 & 0.9083 & 0.9038 \\
\hline 0.06 & $\mathrm{BE}$ & 0.9446 & 0.9400 & $0.936 /$ & 0.9332 & 0.9295 & 0.9250 & 0.9208 & 0.9185 & 0.9130 & 0.9089 & 0.9049 \\
\hline 700 & $\mathrm{HE}$ & 09364 & 09318 & 2 & 09244 & 0 & 09160 & 09123 & 0.9071 & 0.9024 & 0.8977 & 0.8930 \\
\hline I. & $\mathrm{BE}$ & 0.9504 & 0.9510 & 0.9202 & $0.9<44$ & 0.9200 & 0.9160 & 0.9123 & 0.9094 & 0.9032 & 0.8991 & 0.8956 \\
\hline & $\mathrm{HE}$ & & & & & 0.9116 & 0 & & 0.8980 & 0.8929 & 0.8878 & 0.8827 \\
\hline 0.08 & $\mathrm{BE}$ & $0.92 / 9$ & 0.9242 & 0.9204 & 0.9161 & 0.9122 & $0.90 / 5$ & 0.9031 & 0.9003 & 0.8934 & 0.8898 & 0.8860 \\
\hline מח & $\mathrm{HE}$ & ברחק & $001{ }^{2}$ & זרים & קרח & & 0.8990 & 0.8938 & 0.8896 & 0.8844 & 0.8789 & 0.8734 \\
\hline 0.09 & $\mathrm{BE}$ & $0.9<00$ & 0.9104 & 0.9123 & 0.9015 & 0.9039 & 0.8997 & 0.8947 & 0.8912 & 0.8842 & 0.8805 & 0.8769 \\
\hline 018 & $\mathrm{HE}$ & 001 & 00001 & 0004 & ת & 0005 & 0 0000 & & 0.8812 & 0.8762 & 0.8700 & 0.8650 \\
\hline 0.10 & $\mathrm{BE}$ & 0.9121 & 0.9081 & 0.9041 & 0.8998 & 0.8954 & 0.8909 & 0.8862 & 0.8834 & 0.8756 & 0.8715 & 0.8681 \\
\hline
\end{tabular}


Table 2. Optimal damping ratio of the DVA

\begin{tabular}{|c|c|c|c|c|c|c|c|c|c|c|c|c|}
\hline & & $\xi_{1}=0.0$ & $\xi_{1}=0.01$ & $\xi_{1}=0.02$ & $\xi_{1}=0.03$ & $\xi_{1}=0.04$ & $\xi_{1}=0.05$ & $\xi_{1}=0.06$ & $\xi_{1}=0.07$ & $\xi_{1}=0.08$ & $\xi_{1}=0.09$ & $\xi_{1}=0.1$ \\
\hline$\mu$ & excitation & $\xi_{2}{ }^{o p t}$ & $\xi_{2}{ }^{o p t}$ & $\xi_{2}{ }^{o p t}$ & $\xi_{2}$ opt & $\xi_{2}{ }^{o p t}$ & $\xi_{2}{ }^{o p t}$ & $\xi_{2}$ opt & $\xi_{2}{ }^{o p t}$ & $\xi_{2}{ }^{o p t}$ & $\xi_{2}{ }^{o p t}$ & $\xi_{2}{ }^{o p t}$ \\
\hline \multirow{2}{*}{0.01} & $\mathrm{HE}$ & \multirow{2}{*}{0.0624} & \multirow{2}{*}{0.0177} & \multirow{2}{*}{0.0184} & \multirow{2}{*}{0.0303} & \multirow{2}{*}{0.0361} & 0.0497 & 0.0556 & \multirow{2}{*}{0.0653} & \multirow{2}{*}{0.0719} & 0.0766 & 0.0812 \\
\hline & $\mathrm{BE}$ & & & & & & 0.0527 & 0.0514 & & & 0.0765 & 0.0823 \\
\hline \multirow{2}{*}{0.02} & $\mathrm{HE}$ & \multirow{2}{*}{0.0927} & \multirow{2}{*}{0.0746} & \multirow{2}{*}{0.0743} & \multirow{2}{*}{0.0757} & \multirow{2}{*}{0.0834} & 0.0844 & 0.0933 & \multirow{2}{*}{0.1022} & \multirow{2}{*}{0.1111} & 0.1132 & 0.1152 \\
\hline & $\mathrm{BE}$ & & & & & & 0.0828 & 0.0861 & & & 0.1144 & 0.1164 \\
\hline \multirow{2}{*}{0.03} & $\mathrm{HE}$ & \multirow{2}{*}{0.1036} & \multirow{2}{*}{0.1233} & \multirow{2}{*}{0.1256} & \multirow{2}{*}{0.1276} & \multirow{2}{*}{0.1296} & \multirow{2}{*}{0.1316} & 0.1328 & \multirow{2}{*}{0.1335} & 0.1339 & 0.1329 & \multirow{2}{*}{0.1313} \\
\hline & $\mathrm{BE}$ & & & & & & & 0.1253 & & 0.1343 & 0.1327 & \\
\hline \multirow{2}{*}{0.04} & $\mathrm{HE}$ & \multirow{2}{*}{0.1134} & \multirow{2}{*}{0.1411} & \multirow{2}{*}{0.1403} & \multirow{2}{*}{0.1395} & \multirow{2}{*}{0.1384} & \multirow{2}{*}{0.1373} & 01363 & 0.1351 & 0.1335 & 0.1319 & 0.1303 \\
\hline & $\mathrm{BE}$ & & & & & & & 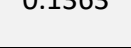 & 0.1352 & 0.1376 & 0.1404 & 0.1315 \\
\hline 005 & $\mathrm{HE}$ & 0 & 01465 & 01464 & 01163 & 0 1462 & 1475 & 01484 & 0.1489 & 0.1449 & 0.1499 & 0.1504 \\
\hline 0.0 & $\mathrm{BE}$ & ..1LJ2 & J & 0.1404 & 0.1405 & 0.1402 & 0.1478 & 0.14404 & 0.1369 & 0.1438 & 0.1487 & 0.1332 \\
\hline & $\mathrm{HE}$ & 0 & 01513 & 01512 & 1511 & 1510 & 0.1509 & 0.1500 & 0.1491 & 0.1482 & 0.1473 & 0.1464 \\
\hline 0.00 & $\mathrm{BE}$ & 0.1311 & כונד. & & ט.11 & 0.10 & 0.1577 & 0.1605 & 0.1358 & 0.1506 & 0.1499 & 0.1354 \\
\hline 0 & $\mathrm{HE}$ & O 1378 & 1506 & 01506 & 01505 & 1504 & 0.1502 & 1505 & 0.1508 & 0.1525 & 0.1542 & 0.1559 \\
\hline 0.07 & $\mathrm{BE}$ & סקד. & .1500 & .1500 & כ & 0.1504 & 0.1621 & כטנה. & 0.1377 & 0.1555 & 0.1519 & 0.1379 \\
\hline 0 & $\mathrm{HE}$ & 0147 & 1187 & 01106 & 1504 & 0.1509 & O 1514 & 01523 & 0.1552 & 0.1571 & 0.1552 & 0.1533 \\
\hline 0.08 & $\mathrm{BE}$ & 0.1441 & 0.1401 & 0.1490 & 0.1504 & 0.1512 & 0.1514 & 0.1333 & 0.1396 & 0.1604 & 0.1544 & 0.1401 \\
\hline רחת & $\mathrm{HE}$ & 01516 & 1510 & 1507 & 1514 & 0 & 0.1528 & 0.1555 & 0.1582 & 0.1620 & 0.1659 & 0.1698 \\
\hline 0.0 & $\mathrm{BE}$ & טגנה. & טגנה.ר & ועם & . & $0.15<1$ & 0.1513 & 0.1553 & 0.1415 & 0.1648 & 0.1569 & 0.1428 \\
\hline & $\mathrm{HE}$ & 1585 & 01585 & 1585 & 158? & 1580 & 1577 & 1575 & 0.1572 & 0.1569 & 0.1572 & 0.1569 \\
\hline & $\mathrm{BE}$ & & & & & & & בונד. & 0.1432 & 0.1698 & 0.1592 & 0.1458 \\
\hline
\end{tabular}

Figure 8 depicts the FRC curve for the considered primary system with harmonic excitation in the frequency range $\Omega \in[0.1,2]$, the mass ratio $\mu=0.1$ and the optimum parameters $\varepsilon^{\text {opt }}$ and $\xi^{\text {opt }}$ are found in table 1 and 2 , respectively. Figure 8(a) shows the response for the undamped primary system while the other cases are for a damped primary system. It can be seen from figure 8 that for all cases the two peaks are on the same level, showing that our approach captures the optimal solution.

The FRC curves shown in figure 9 were constructed for oscillator subjected to base excitation, $\Omega \in[0.1,2]$ and mass ratio $\mu=0.07$ and, again, the optimal parameters $\varepsilon^{o p t}$ and $\xi^{o p t}$ can be found in the table 1 and 2 , respectively. Figure 9(a) shows the response for undamped primary system while the other cases are for a damped primary system. As can be seen, the general behavior of the oscillator for different damping ratios in the primary system is satisfactory in the sense that the two peaks are on the same level, thus our approach has been validated for this reference parameters for the case of base excitation. 


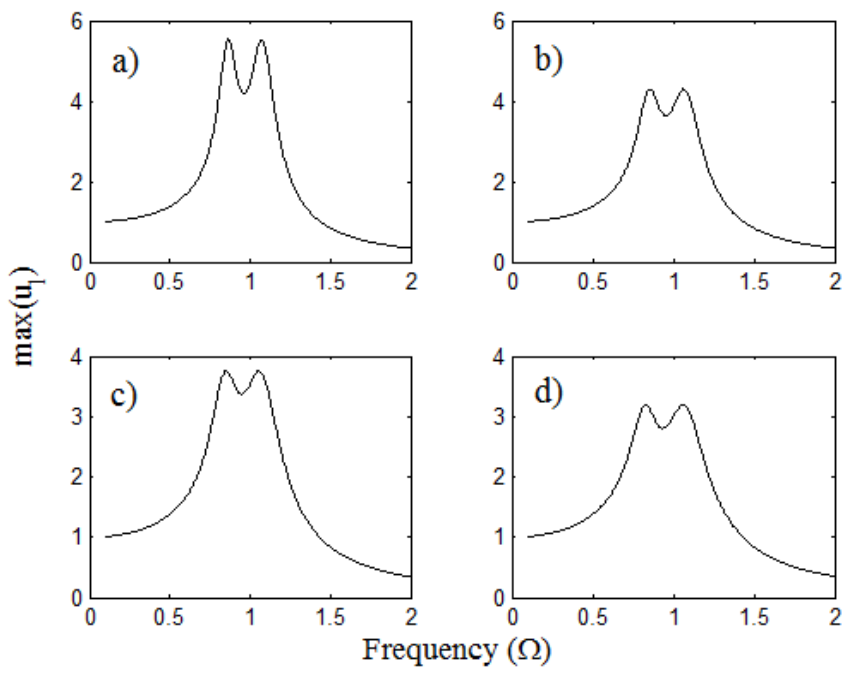

Figure 8: Response curves for harmonic excitation for $\mu=0.1$ with $\varepsilon^{o p t}$ and $\xi^{o p t}$ obtained by tables 1 and 2: a) $\xi_{1}=0.0$, b) $\xi_{1}=0.04$, c) $\xi_{1}=0.07$, d) $\xi_{1}=0.09$.

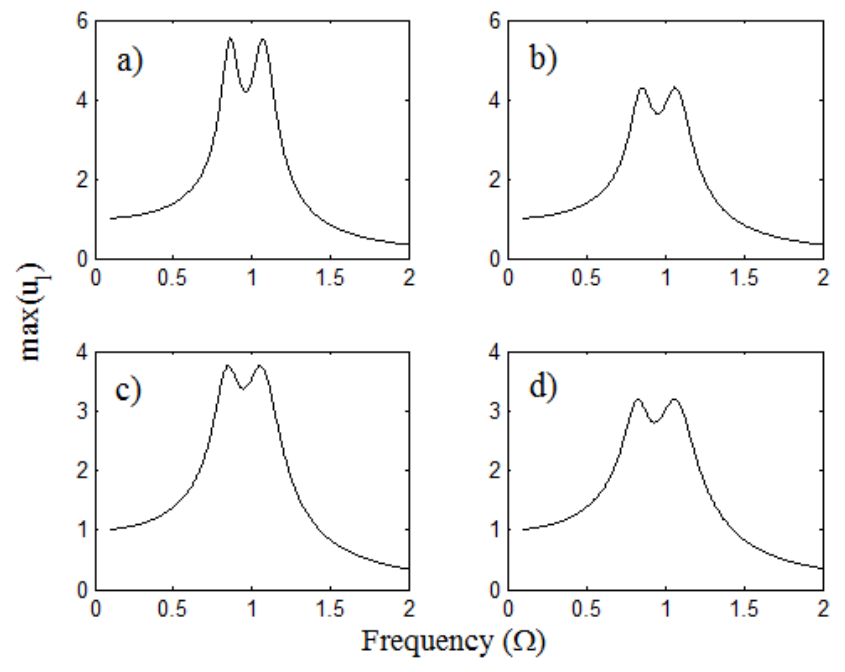

Figure 9: Response curves for base excitation and $\mu=0.07$ with $\varepsilon^{o p t}$ and $\xi^{o p t}$ obtained by tables 1 and $\left.\left.2: \mathrm{a}\right) \xi_{1}=0.0, \mathrm{~b}\right) \xi_{1}=0.03$, c) $\xi_{1}=0.05$, d) $\xi_{1}=0.08$

\section{BILINEAR INTERPOLATION}

Interpolation is the method that allows constructing a new dataset from a discrete set of previously known points. Linear interpolation is an interpolation method that uses a linear function $p(x)$ (a first-degree polynomial) to approximate an assumed function $f(x)$.

Bilinear interpolation is an extension of linear interpolation that permits to interpolate functions of two variables in a regular grid. The key idea is to perform linear interpolation, first in one direction, and then again in the other direction. The bilinear interpolation uses the weighted average of the original values that are around the new values. 
Since we know the value of an unknown function $f(x)$ at four points $P_{11}=\left(x_{1}, y_{1}\right), P_{12}=\left(x_{1}, y_{2}\right), P_{21}=\left(x_{2}, y_{1}\right)$, $P_{22}=\left(x_{2}, y_{2}\right)$, we want to find the value of the function at a point $R=(x, y)$, where we defined the point $P_{i j}(i, j=1,2)$ as node, and $R$ is the point where we want to perform the interpolation (see figure 10).

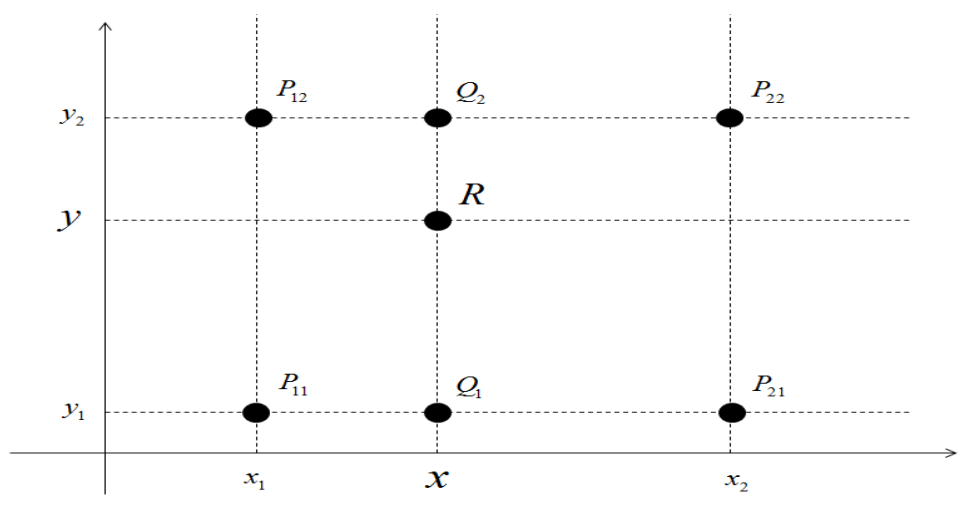

Figure 10. Bilinear interpolation

First we interpolate in the $\mathrm{x}$ - direction:

$f\left(Q_{1}\right) \approx \frac{x_{2}-x}{x_{2}-x_{1}} f\left(P_{11}\right)+\frac{x-x_{1}}{x_{2}-x_{1}} f\left(P_{21}\right)$

$f\left(Q_{2}\right) \approx \frac{x_{2}-x}{x_{2}-x_{1}} f\left(P_{12}\right)+\frac{x-x_{1}}{x_{2}-x_{1}} f\left(P_{22}\right)$

where $Q_{1}=\left(x, y_{1}\right) ; Q_{2}=\left(x, y_{2}\right)$

We then proceed with the interpolation in $\mathrm{y}$ :

$f(R) \approx \frac{y_{2}-y}{y_{2}-y_{1}} f\left(Q_{1}\right)+\frac{y-y_{1}}{y_{2}-y_{1}} f\left(Q_{2}\right)$

Substituting equations (13) and (14) into equation (15), we obtain,

$f(x, y) \approx \frac{f\left(P_{11}\right)}{\left(x_{2}-x_{1}\right)\left(y_{2}-y_{1}\right)}\left(x_{2}-x\right)\left(y_{2}-y\right)+\frac{f\left(P_{21}\right)}{\left(x_{2}-x_{1}\right)\left(y_{2}-y_{1}\right)}\left(x-x_{1}\right)\left(y_{2}-y\right)+\frac{f\left(P_{12}\right)}{\left(x_{2}-x_{1}\right)\left(y_{2}-y_{1}\right)}\left(x_{2}-x\right)\left(y-y_{1}\right)+$ $\frac{f\left(P_{22}\right)}{\left(x_{2}-x_{1}\right)\left(y_{2}-y_{1}\right)}\left(x-x_{1}\right)\left(y-y_{1}\right)=\frac{1}{\left(x_{2}-x_{1}\right)\left(y_{2}-y_{1}\right)}\left[x_{2}-x x-x_{1}\right]\left[\begin{array}{ll}f\left(P_{11}\right) & f\left(P_{12}\right) \\ f\left(P_{21}\right) & f\left(P_{22}\right)\end{array}\right]\left[\begin{array}{l}y_{2}-y_{1} \\ y-y_{1}\end{array}\right]$

Therefore;

$f(x, y)=\frac{1}{\left(x_{2}-x_{1}\right)\left(y_{2}-y_{1}\right)}\left[x_{2}-x x-x_{1}\right]\left[\begin{array}{ll}f\left(P_{11}\right) & f\left(P_{12}\right) \\ f\left(P_{21}\right) & f\left(P_{22}\right)\end{array}\right]\left[\begin{array}{l}y_{2}-y_{1} \\ y-y_{1}\end{array}\right]$

Here we propose to use the optimal values given by tables 1 and 2 as nodes of the bilinear interpolation and for any pair of $\left(\xi_{1}, \mu\right)$, the equation (17) is used to obtain the optimal values of $\varepsilon$ and $\xi_{2}$. A schematic drawing of the bilinear interpolation applied to the design of the DVA parameters based on the values of the tables 1 and 2 are presented in figures 11 and 12 . As can be seen from figure 11, the nodes were taken as known parameters $\varepsilon^{o p t}$ that can be found in table 1 , and choosing $\left(\xi_{1}, \mu\right)$ inside the box formed by the nodes $\varepsilon^{o p t}\left(\xi_{1}^{b}, \mu^{b}\right), \varepsilon^{o p t}\left(\xi_{1}^{b}, \mu^{a}\right)$, $\varepsilon^{o p t}\left(\xi_{1}^{a}, \mu^{b}\right), \varepsilon^{o p t}\left(\xi_{1}^{a}, \mu^{a}\right)$ it is possible to obtain the expressions for the optimum parameters $\varepsilon^{o p t}\left(\xi_{1}, \mu\right)$ through the bilinear interpolation. Here the subscript $a$ represent the value after the selected value of $\xi_{1}$ (or $\mu$ ), and $b$ is the value before the $\xi_{1}$ (or $\mu$ ). 
Table 1

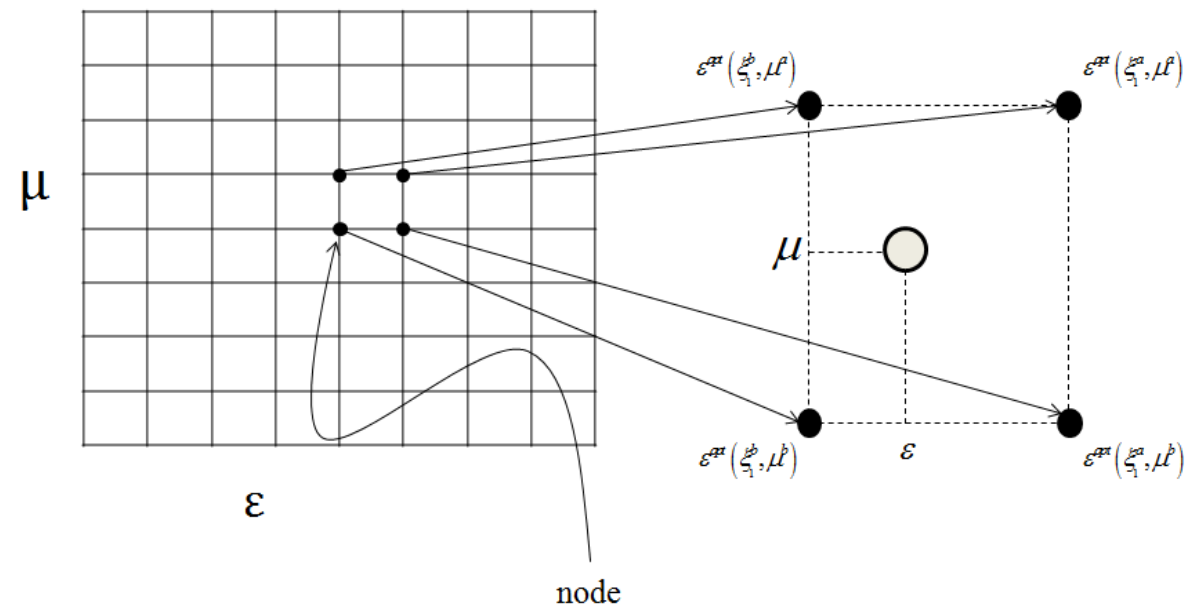

Figure 11. 4 optimal values of $\varepsilon^{o p t}$ obtained from table 1 surrounding an unknown value of $\varepsilon$ for the coordinates $\left(\xi_{1}, \mu\right)$.

In an analogous way we can define the nodes $\xi_{2}^{o p t}\left(\xi_{1}^{b}, \mu^{b}\right), \xi_{2}^{o p t}\left(\xi_{1}^{b}, \mu^{a}\right), \xi_{2}^{o p t}\left(\xi_{1}^{a}, \mu^{b}\right), \xi_{2}^{o p t}\left(\xi_{1}^{a}, \mu^{a}\right)$ (extracted from table 2 ) in order to obtain the expressions for the optimal parameters $\xi_{2}^{o p t}$ given the values of $\xi_{1}$ and $\mu$ (see figure 12 ).

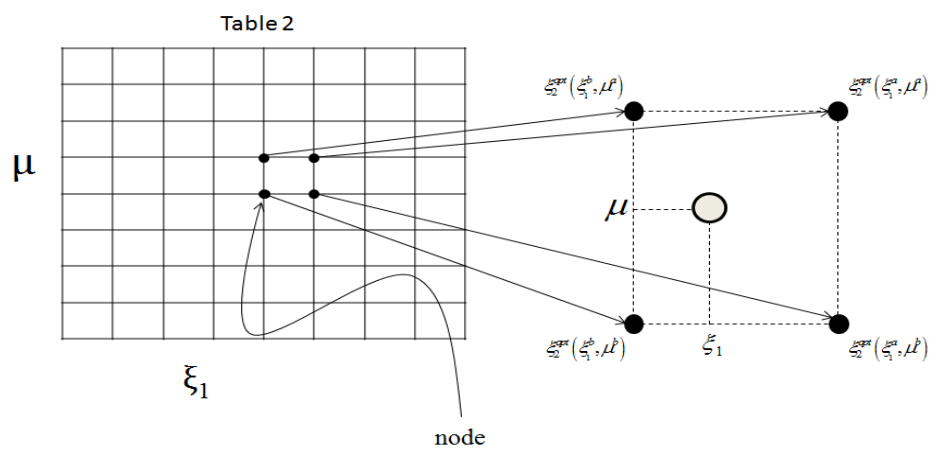

Figure 12: 4 optimal values of $\xi_{2}^{o p t}$ obtained from table 2 surrounding an unknown value of $\xi_{2}$ for the coordinates $\left(\xi_{1}, \mu\right)$.

Therefore, using the equation (17), the expressions for the optimal parameters are;

$\varepsilon^{o p t}\left(\xi_{1}, \mu\right)=\frac{1}{\left(\xi_{1}^{a}-\xi_{1}\right)\left(\mu^{a}-\mu\right)}\left[\xi_{1}^{a}-\xi_{1} \xi_{1}-\xi_{1}^{b}\right]\left[\begin{array}{ll}\varepsilon^{o p t}\left(\xi_{1}^{b}, \mu^{b}\right) & \varepsilon^{o p t}\left(\xi_{1}^{b}, \mu^{a}\right) \\ \varepsilon^{o p t}\left(\xi_{1}^{a}, \mu^{b}\right) & \varepsilon^{o p t}\left(\xi_{1}^{a}, \mu^{a}\right)\end{array}\right]\left[\begin{array}{l}\xi_{1}^{a}-\xi_{1} \\ \xi_{1}-\xi_{1}^{b}\end{array}\right]$

$\xi_{2}^{o p t}\left(\xi_{1}, \mu\right)=\frac{1}{\left(\xi_{1}^{a}-\xi_{1}\right)\left(\mu^{a}-\mu\right)}\left[\xi_{1}^{a}-\xi_{1} \xi_{1}-\xi_{1}^{b}\right]\left[\begin{array}{ll}\xi_{2}^{o p t}\left(\xi_{1}^{b}, \mu^{b}\right) & \xi_{2}^{o p t}\left(\xi_{1}^{b}, \mu^{a}\right) \\ \xi_{2}^{o p t}\left(\xi_{1}^{a}, \mu^{b}\right) & \xi_{2}^{o p t}\left(\xi_{1}^{a}, \mu^{a}\right)\end{array}\right]\left[\begin{array}{l}\xi_{1}^{a}-\xi_{1} \\ \xi_{1}-\xi_{1}^{b}\end{array}\right]$

It is worth mentioning here that we do not prove that these solutions obtained by the bilinear interpolation (equations (18) and (19)) are optimal (in the Den Hartog sense), but based on numerical evaluations, we conjecture that it holds for any pair of $\left(\xi_{1}, \mu\right)$.. For all of the tests performed the difference between the two peaks obtained in FRC curve was maintained below of $\delta \leq 10^{-2}$.

For example, if we let $\xi_{1}=0.043$ and $\mu=0.029$, and assuming $\xi_{1}^{a}=0.05, \xi_{1}^{b}=0.04, \mu^{a}=0.03, \mu^{b}=0.02$ then from tables 1 and 2, we have $\varepsilon^{o p t}\left(\xi_{1}^{b}, \mu^{b}\right)=0.9713, \xi_{2}^{o p t}\left(\xi_{1}^{b}, \mu^{b}\right)=0.0834, \varepsilon^{o p t}\left(\xi_{1}^{b}, \mu^{a}\right)=0.9594, \xi_{2}^{o p t}\left(\xi_{1}^{b}, \mu^{a}\right)=$ $0.1296, \varepsilon^{o p t}\left(\xi_{1}^{a}, \mu^{b}\right)=0.9683, \xi_{2}^{o p t}\left(\xi_{1}^{a}, \mu^{b}\right)=0.0844, \varepsilon^{o p t}\left(\xi_{1}^{a}, \mu^{a}\right)=0.9565, \xi_{2}^{o p t}\left(\xi_{1}^{a}, \mu^{a}\right)=0.1316$, and using the equations 18 and 19 , we obtain $\varepsilon^{o p t}(0.043,0.29)=0.9598, \xi_{2}^{o p t}(0.043,0.29)=0.1255$. Using this values of $\varepsilon^{o p t}$ and $\xi_{2}^{o p t}$ the FRC curve have been evaluated and presented in figure 13. As can be seen in both cases the magnitude of the peaks is very close to each other shows that these two parameters are optimal (in a Den Hartog sense). 
The FRC curves plotted for different values of $\xi_{1}$ and $\mu$ are presented in figure 14 (harmonic excitation) and figure 15 (base excitation). As it can be seen, the values of $\varepsilon^{o p t}$ and $\xi_{2}^{o p t}$ found by equations (18) and (19) are optimal in the Den Hartog sense, once the peaks frequency response is in the same level when the oscillator is subject to a harmonic excitation or a base excitation. The results presented here are consistent with the equal peak methodology.
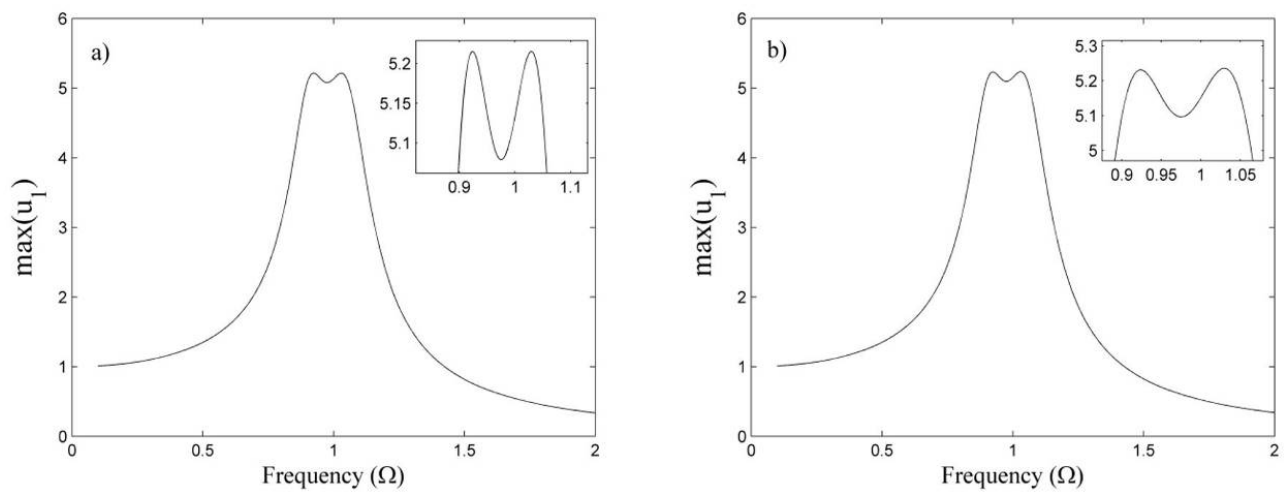

Figure 13. $F R C$ response for $\varepsilon^{o p t}=0.9598, \xi_{2}^{o p t}=0.1255$ and $\left(\xi_{1}, \mu\right)=(0.043,0.029)$ (a) harmonic excitation and (b) base excitation
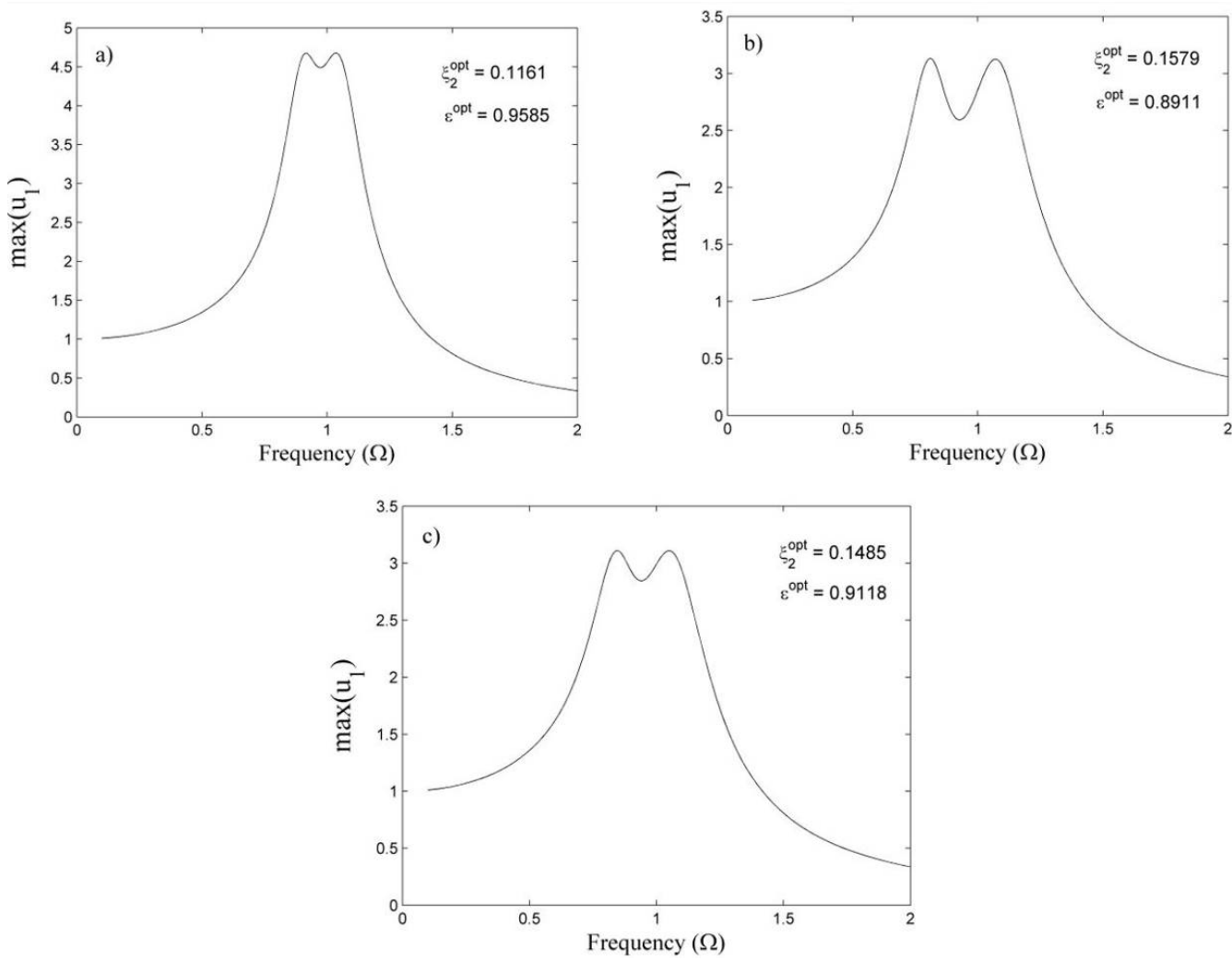

Figure 14. FRC curves for harmonic excitation: (a) $\left(\xi_{1}, \mu\right)=(0.058,0.026)$, (b) $\left(\xi_{1}, \mu\right)=(0.072,0.087)$, (c) $\left(\xi_{1}, \mu\right)=(0.093,0.055)$ 

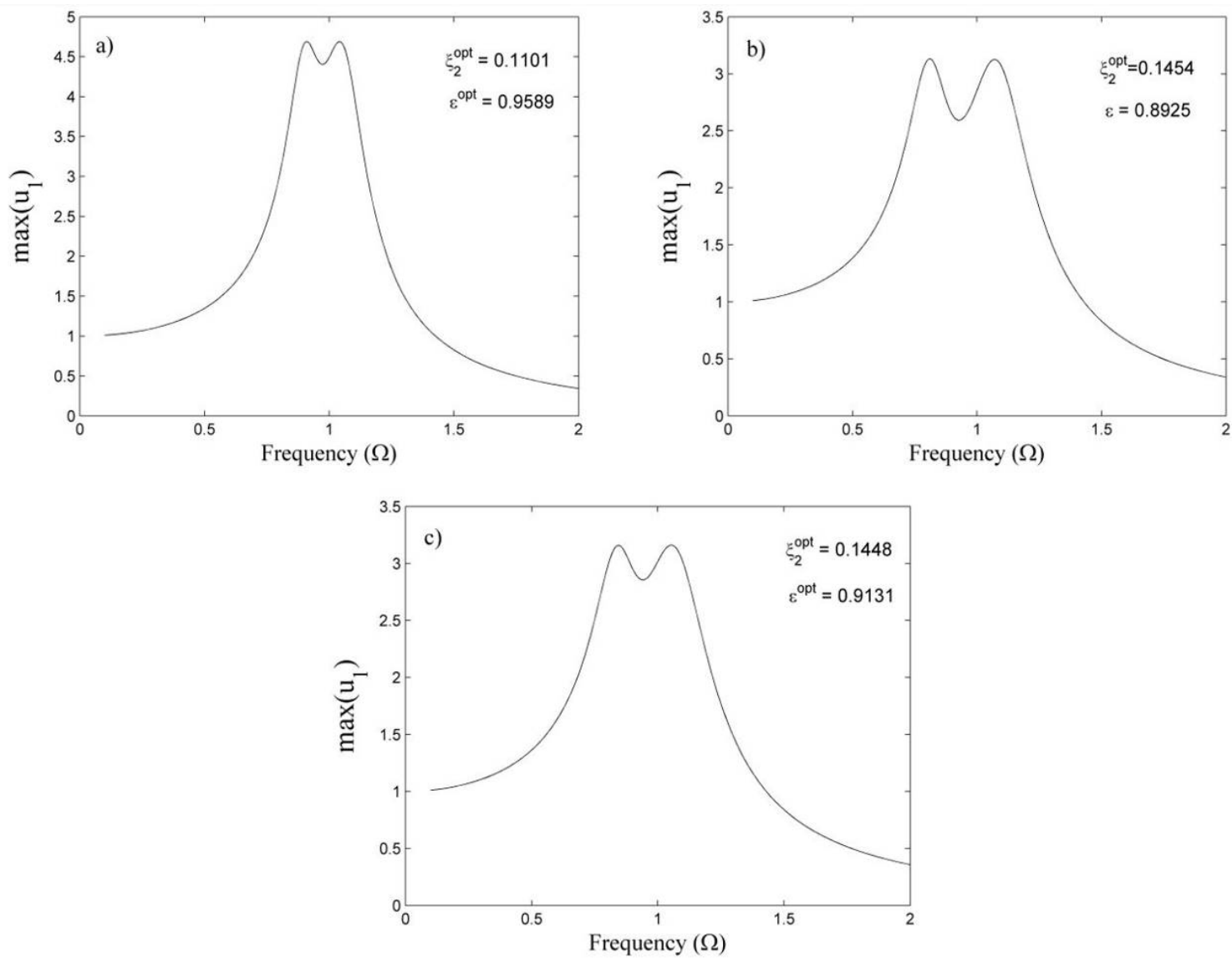

Figure 15: FRC curves for base excitation: $(\mathrm{a})\left(\xi_{1}, \mu\right)=(0.058,0.026),(\mathrm{b})\left(\xi_{1}, \mu\right)=(0.072,0.087),(\mathrm{c})\left(\xi_{1}, \mu\right)=(0.093,0.055)$

\section{COMPARISONS}

In literature is possible to find different kinds of analytical and/or numerical analysis procedures for the estimation of the optimal parameters of damping and tuning frequency. Two objective functions are defined in order to compare the response of the method proposed here with others, such optimization criterions are the $H_{2}$ and $H_{\infty}$ norms.

This two norms are based on the FRCs, the corresponding $H_{2}$ norm and $H_{\infty}$ norm are computed taking into account the presence of the absorber:

$H_{2}=\left(\int_{\Omega}\left|\max \left(u_{1}(\Omega)\right)\right|^{2} d \Omega\right)^{1 / 2}, H_{\infty}=\max _{i}\left|u_{1}\left(\Omega_{\mathrm{i}}\right)\right|$

These two norms were chosen due to their widespread adoption and the large body of existing research. The $H_{2}$ optimization criterion has the objective in minimizing the vibration energy transmitted to the system form de energy source. On the other hand, the $H_{\infty}$ optimization criterion has the objective in minimizing the maximum amplitude response of the system. Considering the primary system without damping and harmonic force excitation the method of comparison was adopted from Den Hartog (1943) and Asami and Nishihara (2003). On the other hand, assuming the viscous damper in the primary system the comparisons were made with loi and Ikeda (1978), Tsai and Guan-Cheng (1993), and Asami et al. (2002) methodologies. For the case of base excitation, the comparison was made with Asami et al. (2002). In order to compare the results among the approaches the parameters $\xi_{1}$ and $\mu$ are the same used in table 1.

\subsection{Undamped primary system}

Two diagrams showing this two norms under varying mass relation $(\mu)$ is shown in Fig. 16. Here we define the subscripts DH as Den Hartog (1943), AN as Asami-Nishihara (2003) and PTB as Piccirillo-Tusset-Balthazar methodologies. The equations of the optimal frequency ratio and optimal damping ratio of $\mathrm{DH}$ method is given in Eq. 6 , AN method is detailed in Appendix A (see Eqs. A1-A2) and PTB method is obtained in tables 1 and 2 . The diagram 
constructed taking into account the difference between the norm $H_{\infty}$ for each methodology is shown in Fig. 16a). First, the profiles show that for almost all values of $\mu, H_{\infty}^{A N B}<H_{\infty}^{D H}$ and $H_{\infty}^{A N B}<H_{\infty}^{P T B}$, confirming that the methodology of Asami and Nishihara [28] is the better approach to obtain the $H_{\infty}$ optimization of the parameters of the DVA. If the comparison is made between the $H_{\infty}^{D H}$ and $H_{\infty}^{P T B}$ yields the conclusion that $H_{\infty}^{P T B}<H_{\infty}^{D H}$ when $\mu \in[0.03,0.04]$ for the other cases $H_{\infty}^{D H}<H_{\infty}^{P T B}$. These results imply that the PTB methodology that realizes equal peaks is not the better strategy to minimize the maximum amplitude response of the undamped primary system. Figure 16(b) shows the comparison among the strategies taking into account the $H_{2}$ criterion. In this case, it should be noted that $H_{2}^{D H}<$ $H_{2}^{A N}$ for all values of $\mu$. Moreover, if $\mu \geq 0.03$ then $H_{2}^{P T B}<\left(H_{2}^{D H}\right.$ or $\left.H_{2}^{A N}\right)$; otherwise $\left(H_{2}^{D H}\right.$ or $\left.H_{2}^{A N}\right)<H_{2}^{P T B}$. Based on these observations, it can be concluded that the best approach with the objective to minimize the maximum amplitude response of the system is the Asami et al. approach. On the other hand, if the objective is to minimize the vibration energy transmitted to the system form the energy source the best approach depends on the value of $\mu$, if $\mu<0.03$ then use Den Hartog methodology, but if $\mu \geq 0.03$ then the best approach is to utilize the Piccirillo-TussetBalthazar methodology.
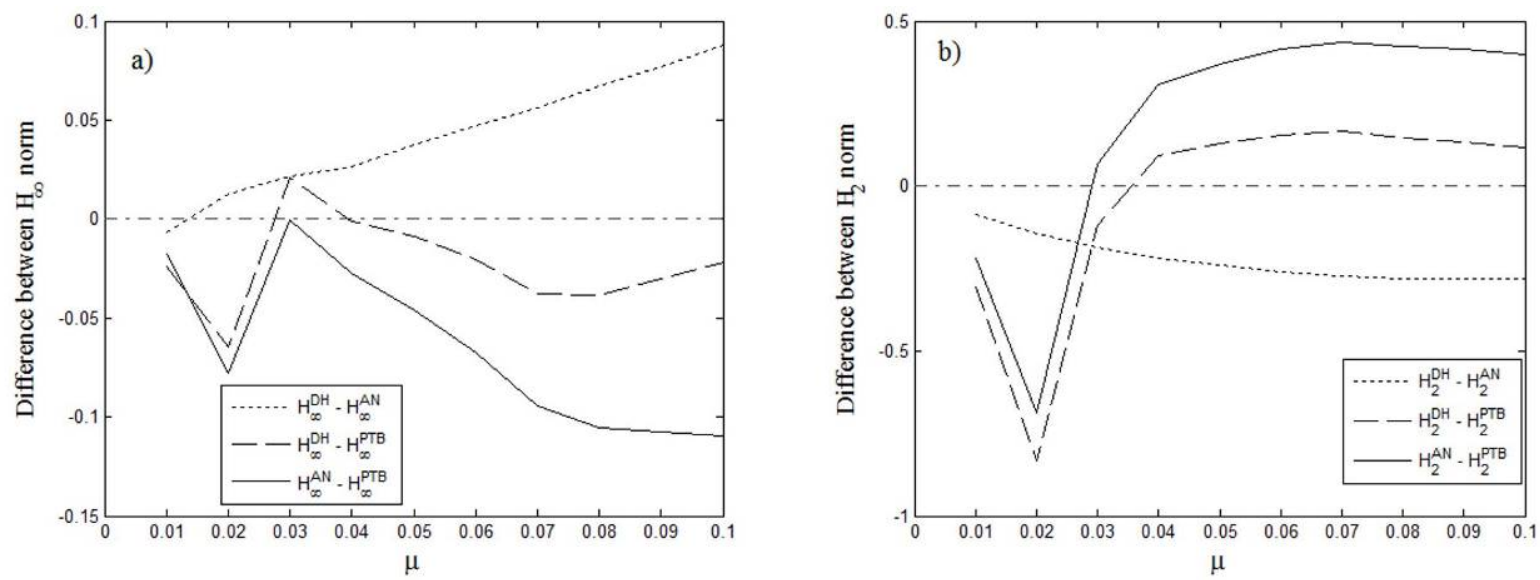

Figure 16: Performance of the norm for different mass ratio with the undamped primary system and harmonic excitation. (a) $H_{\infty}$ and (b) $H_{2}$

\subsection{Harmonic excitation (HE)}

A similar analysis was performed when a damped primary system is considered. The scenario of the $H_{\infty}$ and $H_{2}$ norm evolution are presented in Figs. 17 and 18. Here, the subscripts in those figures represent the methodology adopted: IK is the loi and Ikeda approach (see Eqs. A3-A4), TL is Tsai and Lin approach (see Eqs. A5-A6) and ANB is the Asami-Nishihara-Baz (see Eqs. A7-A12) methodology, and PTB as Piccirillo-Tusset-Balthazar approach. Figure 17 compares the solutions of these different approaches for the conditions when $\mu$ changes and $\zeta_{1}$ is a fixed number. It may be observed that the for all cases $H_{\infty}^{P T B}<H_{\infty}^{A N B}$ and $H_{\infty}^{T L}<H_{\infty}^{P T B}$. On the other hand, when the comparison is made based on our method and the loi and lked approach reads as follows;

$H_{\infty}^{I K}<H_{\infty}^{P T B}$, if $\left\{\begin{array}{c}0.01 \leq \xi_{1} \leq 0.04 \wedge \forall \mu \\ 0.05 \leq \xi_{1} \leq 0.1 \wedge 0.06 \leq \mu\end{array}\right.$

$H_{\infty}^{P T B}<H_{\infty}^{I K}$, otherwise

Comparison of $\mathrm{H}_{2}$ norm among all of the strategies shows that: 


$$
H_{2}^{I K}<H_{2}^{P T B} \text { if } H_{2}^{T L}<H_{2}^{P T B}\left\{\begin{array}{c}
0.01 \leq \xi_{1} \leq 0.02, \mu \in[0.01,0.06] \wedge \mu \neq 0.02 \\
0.03 \leq \xi_{1} \leq 0.04, \mu \in[0.01,0.06] \wedge \mu \neq 0.02 \\
0.05 \leq \xi_{1} \leq 0.06, \mu \in[0.02,0.06) \\
0.07 \leq \xi_{1} \leq 0.1, \mu \in[0.02,0.06)
\end{array}\right.
$$

$$
\begin{aligned}
& H_{2}^{P T B}<H_{2}^{I K} \\
& , \text { otherwise } \\
& H_{2}^{P T B}<H_{2}^{T L}
\end{aligned}
$$

$H_{2}^{A N B}<H_{2}^{P T B}$, if $\left\{\begin{array}{c}0.01 \leq \xi_{1} \leq 0.02, \mu \in[0.01,0.06] \wedge \mu \neq 0.02 \\ 0.03 \leq \xi_{1} \leq 0.04, \mu \in[0.01,0.06) \wedge \mu \neq 0.02 \\ 0.05 \leq \xi_{1} \leq 0.06, \mu \in[0.02,0.07) \\ 0.07 \leq \xi_{1} \leq 0.1, \forall \mu\end{array}\right.$

$$
H_{2}^{P T B}<H_{2}^{A N B} \text {, otherwise }
$$
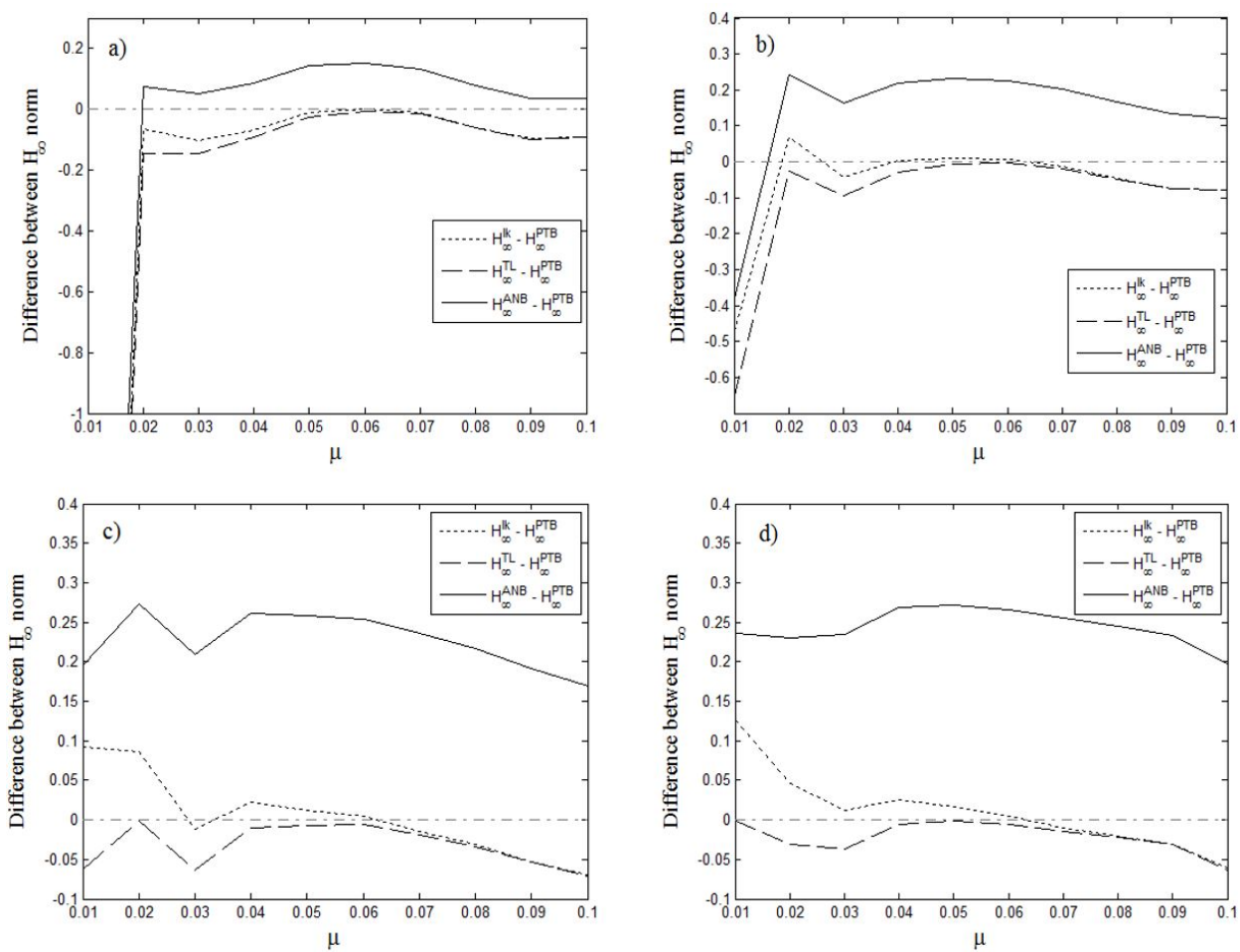

Figure 17: Performance of the $H_{\infty}$ norm for different mass ratio with the damped primary system and harmonic excitation. (a) $\xi_{1}=0.02$, (b) $\xi_{1}=0.04$, (c) $\xi_{1}=0.06$ and (d) $\xi_{1}=0.08$. 

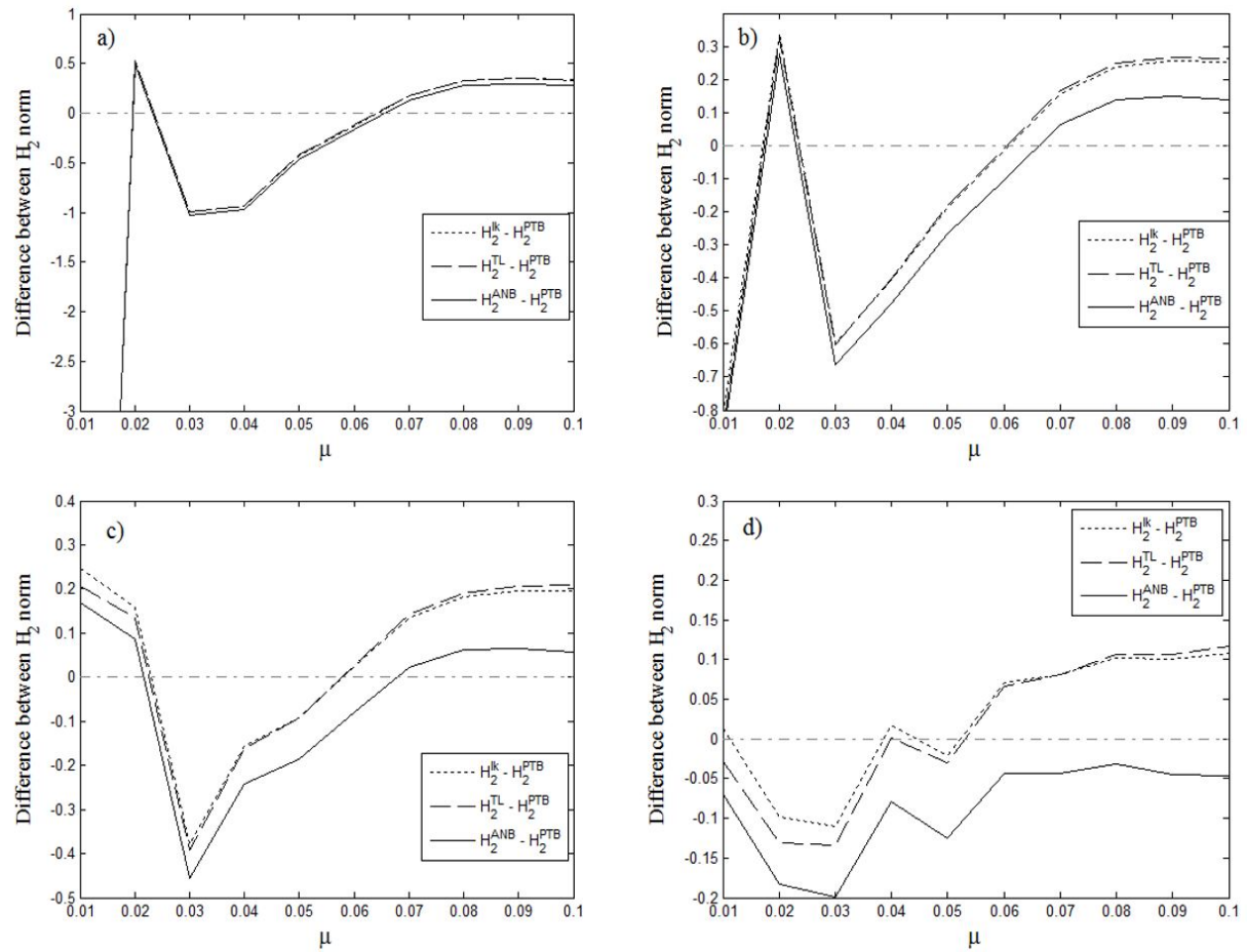

Figure 18: Performance of the $H_{2}$ norm for different mass ratio with the damped primary system and harmonic excitation.

(a) $\xi_{1}=0.01$, (b) $\xi_{1}=0.03$, (c) $\xi_{1}=0.05$ and (d) $\xi_{1}=0.09$.

\subsection{Base excitation (BE)}

Here, the comparison is made between our method and the ANB method (see Eqs. A7-A9 and A13-A15), considering the base excitation. Figure 19 shows two comparisons between the difference of the norms ( $H_{2}$ and $H_{\infty}$ norms) when $\xi_{1}=0.01$ and $\xi_{1}=0.09$. As can be seen from Fig. 19(a) that the values of the difference of norms change to positive or negatives values depending on the value of $\mu$. On the other hand, at $\xi_{1}=0.09$ the values are well defined for all values of $\mu$, that is, $H_{2}^{A N}<$ $H_{2}^{P T B}, \forall \mu$ and $H_{\infty}^{P T B}<H_{\infty}^{A N}, \forall \mu$. Based on figure 19(b), it can be concluded that the best approach with the objective to minimize the maximum amplitude response of the system is the PTB approach. On the other hand, if the objective is to minimize the vibration energy transmitted to the system form the energy source the best approach is the AN approach.
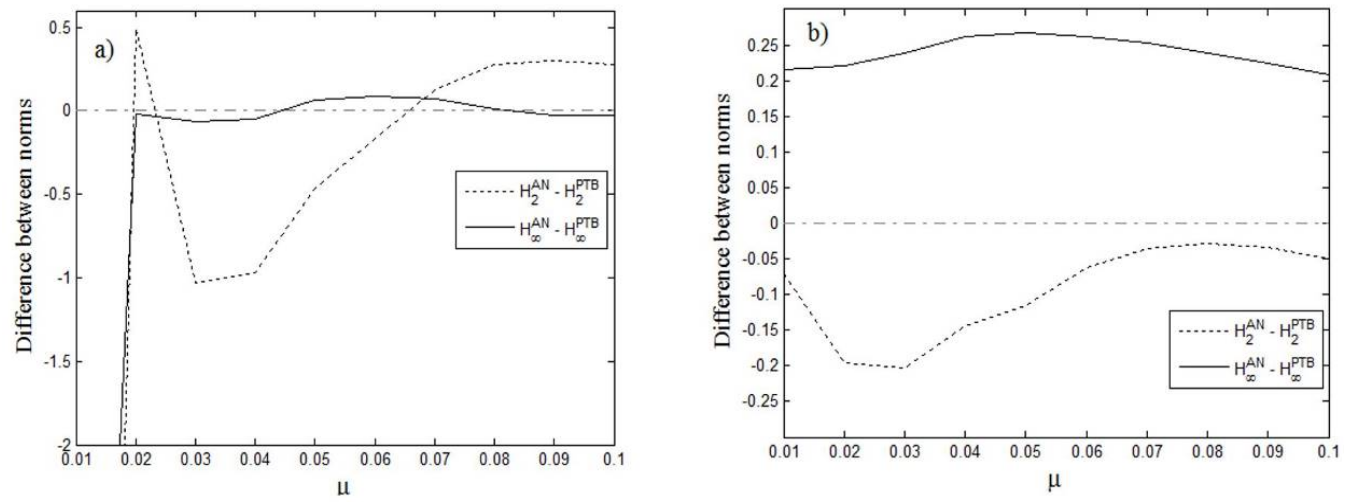

Figure 19: Performance of the norms for different mass ratio with the damped primary system and base excitation. (a) $\xi_{1}=0.01$ and (b) $\xi_{1}=0.09$.

In order to quantify the regions where one strategy is better than another, of course, depending on the norm that you wishes to minimize, the following divisions are presented below; 


$$
\begin{gathered}
H_{2}^{A N}<H_{2}^{P T B} \text {, if }\left\{\begin{array}{c}
0.01 \leq \xi_{1} \leq 0.04, \mu \in[0.01,0.07) \wedge \mu \neq 0.02 \\
\xi_{1}=0.05 \mu \in(0.02,0.08) \\
\xi_{1}=0.06, \mu \in(0.02,0.07) \\
\xi_{1}=0.07, \mu \in(0.05,0.09)
\end{array}\right. \\
H_{2}^{P T B}<H_{2}^{A N B}, \text { otherwise } \\
H_{\infty}^{A N}<H_{\infty}^{P T B}, \text { if } \xi_{1}=0.01 \mu \in[0.01,0.04) \cup(0.08,0.1] \\
H_{\infty}^{P T B}<H_{\infty}^{A N B}, \text { otherwise }
\end{gathered}
$$

\section{CONCLUSIONS}

In this work, the effectiveness of a dynamic vibration absorber (DVA) device in reducing the oscillations of a mechanical model has been investigated. The investigation has been focused on the design improvement of a DVA when the primary system is subject to a harmonic or base excitation. Since the Den Hartog's formulas are strictly valid only for an undamped primary system or systems with very light damping, we have developed a strategy for both high or light damping coefficient in a primary system. The goal is to obtain the optimal parameters of the absorber, that is, mass, stiffness, and damping. For this, we propose a criterion inspired by Den Hartog to minimize the primary system maximum amplitude. Taking into account this criterion and for a set of reference parameters of the mass ratio and damping ratio of the primary system, tables 1 and 2 was constructed to produce the optimal values, in Den Hartog sense, of the mass and damping ratios of the DVA, independent of the excitation. Based on the optimal results expressed in table 1 and 2, analytical formulas of the optimal mass and damping ratios are derived for the absorber assuming the bilinear interpolation. We show with numerical examples that the results of our approach lead to the design of an absorber with excellent performance in a relatively large range of damping values of the primary system and ratio between the masses of the primary system and the absorber. The obtained results point out that the absorber can be an effective tool towards the reduction of the vibration amplitude of the main system and then the possible damage to the structure.

\section{ACKNOWLEDGEMENTS}

The authors acknowledge support by Conselho Nacional de Desenvolvimento Científico e Tecnológico - CNPq, the Brazilian research funding agencies.

\section{References}

Asami, T., Nishihara, O., (2003). Closed-form exact solution to Ho optimization of dynamic vibration absorbers (application to different transfer functions and damping systems), J. Vib. Acoustics 125, 398-405.

Asami, T., Nishihara, O., Baz, A. M., (2002). Analytical solutions to $\mathrm{H}_{\infty}$ and $\mathrm{H}_{2}$ optimization of dynamic vibration absorbers attached to damped linear systems, J. Vib. and Acoustics 124, 284-295.

Ashour, O. N., Nayfeh, A. H., (2003). Experimental and numerical analysis of a nonlinear vibration absorber for the control of plate vibrations, J. Vib. Contr. 9, 209-234.

Brown, B., Singh, T., (2011). Minimax Design of Vibration Absorbers for Linear Damper Systems, J. Sound Vib. 330,2437 - 2448.

Carpineto, N., Lacarbonara, W., Vestroni, F., (2014). Hysteretic Tuned Mass Dampers For Structural vibration mitigation, J. Sound Vib. 333, $1302-1318$.

Cheung, Y. L., Wong, W. O., (2008). Isolation of bending vibration in a beam structure with a translational vibration absorber and a rotational vibration absorber, J. Vib. Contr. 14, 1231-1246.

De Espíndola, J. J., Bavastri, C.A., De Oliveira Lopes, E. M., (2008). Design of optimum systems of viscoelastic vibration absorbers for a given material based on the fractional calculus model, J. Vib. Contr. 14, 1607-1630.

Den Hartog. J.P., (1943). Mechanical Vibrations, McGraw-Hill, New York. 
Doubrawa Filho, F. J., Luersen, M. A., Bavastri, C. A., (2011). Optimal design of viscoelastic vibration absorbers for rotating systems, J. Vib. Contr. 17, 699-710.

Elahinia, M. H., Koo, J. H., Tan, H., (2005). Improving robustness of tuned vibration absorbers using shape memory alloys, Shock Vib. 12, 349-361.

Frahm, H., (1909). Device for damping vibrations of bodies, US No. Patent 989958.

Guo, A. X., Xu, Y. L., Wu, B. (2002). Seismic reliability analysis of hysteretic structure with viscoelastic damp-ers. Engineering structures, 24(3), 373-383.

Habib, G., Detroux, T., Viguié, R., Kerschen, G., (2015). Nonlinear generalization of Den Hartog's equal-peak method, Mech. Syst. Signal Process. 52, 17 - 28.

Ioi, T., Ikeda, K., (1978). On the dynamic vibration damped absorber of the vibration system, Bulletin of JSME 21, 64-71.

Jordanov, I. N., Cheshankov, B. I., (1988). Optimal design of linear and nonlinear dynamic vibration absorbers, J. Sound Vib. $123,157-170$.

Oliva, M., Barone, G., Navarra, G., (2017). Optimal design of Nonlinear Energy Sinks for SDOF structures subjected to white noise base excitations, Eng. Struct. 145, 135-152.

Ormondroyd, J. and Den Hartog, J.P.,The theory of the dynamical vibration absorber. ASME Journal of Ap-plied, 1928.

Oueini, S. S., Nayfeh, A. H., (2000). Analysis and application of a nonlinear vibration absorber, J. Vib. Control 6, 999-1016.

Ouled Chtiba, M., Choura, S., El-Borgi, S., Nayfeh, A. H., (2010b). Confinement of vibrations in flexible structures using supplementary absorbers: dynamic optimization, J. Vib. Contr. 16, 357-376.

Ouled Chtiba, M., Choura, S., Nayfeh, A. H., El-Borgi, S., (2010a). Vibration Confinement and Energy Harvesting in Flexible Structures Using Collocated Absorbers and Piezoelectric Devices, J. Sound. Vib. 329, 261 - 276.

Pai, P. F., Schulz, M. J., (2000). A refined nonlinear vibration absorber, Int. J. Mech. Sci. 42, 537 - 560.

Pennestri, E., (1998). An Application of Chebyshev's Min-Max Criterion to the Optimum Design of a Damped Dynamic Vibration Absorber, J. Sound Vib. 217, 757 - 765.

Piccirillo, V., Balthazar, J. M., Tusset, A. M., Bernardini, D., Rega, G., (2016). Application of a Shape Memory Absorber in Vibration Suppression, App. Mech. Mater. 849, 27-35.

Randall, S. E., Halsted, D. M., Taylor, D. L., (1981). Optimum Vibration Absorber for Linear Damped System, J. Mech. Design $103,908-913$.

Shaw, J., Shaw, S.W., Haddow, A. G., (1989). On the response of the non-linear vibration absorber. Interna-tional Journal of Non-Linear Mechanics, 24, 281 - 293.

Thompson, A. G., (1980). Auxilary Mass Throw in a Tuned and Damped Vibration Absorber, J. Sound Vib. 70, 481 - 486.

Thompson, A. G., (1981). Optimum Tuning and Damping of a Dynamic Vibration Absorber Applied to a Force Excited and Damped Primary System, J. Sound Vib. 77, $403-415$.

Tsai, H. C., Guan-Cheng, L., (1993). Optimum tuned-mass dampers for minimizing steady-state response of support-excited and damped systems, Earthquake Eng. \& Struc. Dyn. 22, 957-973.

Viana, F. A. C., Kotinda, G. I., Rade, D. A., Steffen Jr., V., (2008). Tuning dynamic vibration absorbers by using ant colony optimization, Comp. Struct. 86, 1539 - 1549.

Viguié, R., Kerschen, G., (2009). Nonlinear vibration absorber coupled to a nonlinear primary system: a tuning methodology, J. Sound Vib. 326, 780 - 793.

Wong, W. O., Y. L. Cheung. (2008). Optimal design of a damped dynamic vibration absorber for vibration control of structure excited by ground motion. Engineering Structures 30, 282-286. 


\section{APPENDIX A}

Here the functions of the optimal frequency ratio $\varepsilon^{o p t}$, and optimal damping ratio $\xi_{2}^{o p t}$, for each methodology used in this paper are presented below;

- Asami-Nishihara equations:

$\varepsilon^{o p t}=\frac{2}{1+\mu} \sqrt{\frac{2\left(16+23 \mu+9 \mu^{2}+2(2+\mu) \sqrt{4+3 \mu}\right)}{3\left(64+80 \mu+27 \mu^{2}\right)}}$

$\xi_{2}^{o p t}=\frac{1}{4} \sqrt{\frac{8+9 \mu-4 \sqrt{4+3 \mu}}{1+\mu}}$

- Ioi and Ikeda equations:

$\varepsilon^{o p t}=\frac{1}{1+\mu}-\left(0.241+1.7 \mu-2.6 \mu^{2}\right) \xi_{1}-\left(1-1.9 \mu+\mu^{2}\right) \xi_{1}^{2}$

$\xi_{2}^{o p t}=\sqrt{\frac{3 \mu}{8(1+\mu)}}+\left(0.13+0.12 \mu+0.4 \mu^{2}\right) \xi_{1}-\left(0.01+0.9 \mu+3 \mu^{2}\right) \xi_{1}^{2}$

- Tsai and Lin equations:

$\varepsilon^{o p t}=\frac{1}{1+\mu}+\left(\sqrt{1-2 \xi_{1}^{2}}-1\right)-(1.398+0.26 \sqrt{\mu}-2.004 \mu) \sqrt{\mu} \xi_{1}$

$-(0.362-5.897 \sqrt{\mu}+8.553 \mu) \sqrt{\mu} \xi_{1}^{2}$

$\xi_{2}^{o p t}=\sqrt{\frac{3 \mu}{8(1+\mu)}}+0.15 \xi_{1}-0.321 \xi_{1}^{2}+0.195 \xi_{1} \mu$

- Asami-Nishihara-Baz equations:

$\varepsilon^{o p t}=\frac{1}{1+\mu}-\xi_{1} \frac{1}{1+\mu} \sqrt{\frac{1}{2(1+\mu)}\left(3+4 \mu-\frac{A B}{2+\mu}\right)}+\xi_{1}^{2} \frac{C_{0}-4(5+2 \mu) A B}{4(1+\mu)^{2}(2+\mu)(9+4 \mu)}$

$\xi_{2}^{o p t}=\sqrt{\frac{3 \mu}{8(1+\mu)}}+\xi_{1} \frac{60+63 \mu+16 \mu^{2}-2(3+2 \mu) A B}{8(1+\mu)(2+\mu)(9+4 \mu)}+\xi_{1}^{2} \frac{C_{1}(A+B) \sqrt{2+\mu}+C_{2}(A-B \sqrt{\mu})}{32(1+\mu)(2+\mu)^{2}(9+4 \mu)^{3} \sqrt{2 \mu(1+\mu)}}$

where

$A=\sqrt{3(2+\mu)-\sqrt{\mu(2+\mu)}}, B=\sqrt{3(2+\mu)+\sqrt{\mu(2+\mu)}}$

Being the primary system excited by harmonic force, the following parameters are;

$C_{0}=52+41 \mu+8 \mu^{2}$

$C_{1}=-1296+2124 \mu+6509 \mu^{2}+5024 \mu^{3}+1616 \mu^{4}+192 \mu^{5}$

$C_{2}=48168+112887 \mu+105907 \mu^{2}+49664 \mu^{3}+11632 \mu^{4}+1088 \mu^{5}$

if the base excitation is considered the functions are; 


$$
C_{0}=52+113 \mu+76 \mu^{2}+16 \mu^{3}
$$

$C_{1}=-1296+2124 \mu+7157 \mu^{2}+5924 \mu^{3}+2032 \mu^{4}+256 \mu^{5}$

$$
C_{2}=48168+105111 \mu+91867 \mu^{2}+40172 \mu^{3}+8784 \mu^{4}+768 \mu^{5}
$$

